\title{
Rapid Estimation of Damage to Tall Buildings Using Near Real-Time Earthquake and Archived Structural Simulations
}

\author{
by Swaminathan Krishnan, Emanuele Casarotti, Jim Goltz, Chen Ji, Dimitri Komatitsch, \\ Ramses Mourhatch, Matthew Muto, John H. Shaw, Carl Tape, and Jeroen Tromp
}

\begin{abstract}
This article outlines a new approach to rapidly estimate the damage to tall buildings immediately following a large earthquake. The preevent groundwork involves the creation of a database of structural responses to a suite of idealized ground-motion waveforms. The postevent action involves (1) rapid generation of an earthquake source model, (2) near real-time simulation of the earthquake using a regional spectral-element model of the earth and computing synthetic seismograms at tall building sites, and (3) estimation of tall building response (and damage) by determining the best-fitting idealized waveforms to the synthetically generated ground motion at the site and directly extracting structural response metrics from the database. Here, ground-velocity waveforms are parameterized using sawtoothlike wave trains with a characteristic period (T), amplitude (peak ground velocity, $P G V$ ), and duration (number of cycles, $N$ ). The proof-of-concept is established using the case study of one tall building model. Nonlinear analyses are performed on the model subjected to the idealized wave trains, with $T$ varying from $0.5 \mathrm{~s}$ to $6.0 \mathrm{~s}, P G V$ varying from $0.125 \mathrm{~m} / \mathrm{s}$, and $N$ varying from 1 to 5 . Databases of peak transient and residual interstory drift ratios (IDR), and permanent roof drift are created. We demonstrate the effectiveness of the rapid response approach by applying it to synthetic waveforms from a simulated 1857-like magnitude 7.9 San Andreas earthquake. The peak IDR, a key measure of structural performance, is predicted well enough for emergency response decision making.
\end{abstract}

\section{Introduction}

Recent earthquakes in densely populated parts of the world (e.g., Christchurch, New Zealand; Haiti; Chile; and other locations) have brought added attention to the importance of swift disaster response. The chances of finding survivors buried alive under rubble diminishes rapidly in the hours and first couple of days following the disaster. With the near-certain total failure or partial failure of communication, power, and transportation networks, rapid damage estimation tools could serve as the eyes and ears for emergency response and management to augment information from the USGS ShakeMap and ShakeCast products. ${ }^{1}$ These tools must have the ability to map regions with severe damage and perhaps

\footnotetext{
${ }^{1}$ ShakeMap sites provide near-real-time maps of ground motion and shaking intensity following significant earthquakes. Two types of shakemaps are made available on the Internet: community Internet intensity maps (inferred using feedback from individuals living in the vicinity of an earthquake event about the felt intensity of shaking) and instrumental intensity maps (generated by interpolating data from seismic instruments in the vicinity of the event). The ShakeCast software is an application that automates ShakeMap delivery to critical users and for facilitating notification of shaking levels at user-selected facilities.
}

identify the exact location of collapsed structures so that rescue operations can be prioritized and launched swiftly. Several techniques for detecting regional damage are under development: (1) visually analyzing preevent and postevent high-resolution optical satellite imagery (e.g., Yusuf et al., 2002; Saito et al., 2004; Chiroiu, 2005; Huyck et al., 2005; Saito et al., 2005; Yamazaki et al., 2005), (2) combining seismic intensity data with multitemporal (preevent and postevent) synthetic aperture radar (SAR) data (e.g., Hosokawa et al., 2007; Matsuoka and Nojima, 2010), (3) combining earthquake location information, attenuation relations, and preevent and postevent nighttime city light intensity imagery (e.g., Hayashi et al., 2000; Kohiyama et al., 2004), and (4) comparing preevent and postevent imagery using airborne light detection and ranging (LiDAR) mapping (e.g., Wehr and Lohr, 1999; Markus et al., 2004; Gehbauer et al., 2007; Rehor, 2007; Rehor and Bahr, 2007). Challenges that are hard to overcome for the successful application of these techniques to rapid damage estimation include: (1) cloud cover; (2) differentiating between ground-surface deformations and damage to the built environment; (3) identifying partial 
collapses in the interior that do not affect the exterior form of the structure; (4) data latency and processing times; (5) satellite revisit cycles that could span several days; (6) rationally reconciling imagery from different sources if multiple satellites are used to circumvent the satellite revisit interval problem, among others. Some of these challenges and solutions to overcome them are outlined in Rathje and Adams (2008). While these methods may eventually prove to be effective in identifying regional damage, they may need to be augmented or perhaps even preceded by other faster approaches to estimate the damage state of isolated tall buildings or clusters of tall buildings. The orders of magnitude higher occupancy levels, combined with the shorter survival window associated with partial or total collapse of these special structures ${ }^{2}$ warrants a more targeted rapid damage estimation approach. Structure-specific rapid damage estimation methods given seismic shaking intensity or waveform information are virtually nonexistent, especially for tall buildings. Some techniques, based on comparisons of the capacity spectrum against the demand spectrum (e.g., Yamaguchi et al., 2004) or using structural fragility characteristics to estimate damage given seismic shaking intensity (e.g., Saeki et al., 1999), have been proposed for low-rise structures. However, these techniques do not demonstrably capture tall building damage states effectively. Furthermore, these approaches do not take advantage of recent advances in $3 \mathrm{D}$ seismic-wave propagation simulation capabilities revolutionized by the advent of high-performance computing. Today, near real-time simulations of global earthquakes, producing three-component synthetic seismograms on a dense regional grid, have become possible (Tromp et al., 2010). A natural progression would be the development of a targeted structural damage estimation technique that could take full advantage of the vast synthetically generated seismological data set. Here, we present a method to integrate near real-time seismic waveform simulations with a new tall building damage estimation technique for application to rapid disaster response.

\section{Outline of the Methodology}

Four postevent steps are involved in the rapid response estimation method presented here:

1. Construct a kinematic seismic finite-source model using strong motion, teleseismic, and Global Positioning System (GPS) data.

2. Computationally recreate the earthquake using the spectral-element method, and propagate the seismic waves through a regional earth model from the source to the targeted tall building site.

\footnotetext{
${ }^{2}$ The greater amount of material participating in the collapse of taller buildings lowers the chances for safe pockets of space to be created in the lower stories. The larger impact velocities of the debris from upper stories then increases the likelihood of more severe injuries, which when combined with increased breathing difficulties due to greater airborne debris and dust, lowers the survival time.
}

3. Estimate the performance of the target building under the synthetic three-component ground motion. At tall building sites where reference ground-motion records are available, ${ }^{3}$ these may be used in lieu of the synthetic ground-motion waveforms.

4. Broadcast the results on a secure website for access by emergency management agencies such as the California Emergency Management Agency (CalEMA) and the Federal Emergency Management Agency (FEMA).

Similar ideas have been used in some related applications. For instance, to decide upon whether elevators in a 29 -story building must be brought to a halt at the closest floor in the event of a large earthquake, Kubo et al. (2008) rapidly estimate peak ground velocity (PGV) using a wavenumber integration method as well as the peak response of the building using a linear-elastic single-degree-of-freedom (SDOF) model. Bazzurro et al. (2004) outline a procedure to rapidly determine the residual capacity of low-rise structures to resist aftershocks following a mainshock (in order to assess whether the building is safe for occupation or not). It consists of two preearthquake tasks: performing nonlinear static pushover analyses to anchor various damage states to the roof drift and conducting incremental dynamic analyses (IDA) of SDOF systems starting from each of the damaged states to determine the shaking intensity needed to collapse the damaged structure. To simplify the method, they use an estimate of the median IDA curve that provides a relationship between spectral acceleration and roof drift in lieu of IDA computations. The postearthquake task involves the use of the measured intensity of shaking in the mainshock and the predicted intensity of shaking in a plausible aftershock to tag the building red, yellow, or green.

In the following sections, we present the details of our methodology that specifically targets tall buildings and demonstrate its effectiveness through the example of a hypothetical 1857-like magnitude 7.9 earthquake on the southern San Andreas fault. ${ }^{4}$

\footnotetext{
${ }^{3}$ The International Building Code requires every structure, located where the 1-s spectral response acceleration $S_{1}$ is greater than 0.40 , that either (1) exceeds 6 stories in height with an aggregate floor area of 60,000 square feet $\left(5574 \mathrm{~m}^{2}\right)$ or more, or (2) exceeds 10 stories in height regardless of floor area, to be equipped with not less than three approved recording accelerographs. However, there is no requirement for instruments to be located on tall building sites to record base motion. As a result, ground-motion records at tall building sites are not readily available except in isolated instances. Moreover, the instrumentation in commercial buildings is neither well-maintained nor are the data easily retrievable in most instances (a few federal and state buildings are exceptions).

${ }^{4}$ On 9 January 1857, a large magnitude 7.9 earthquake occurred on the right-lateral strike-slip San Andreas fault, the boundary between the North American and the Pacific plates. Paleoseismological evidence suggests that the rupture initiated in Parkfield in central California, propagated in a southeasterly direction a distance of $360 \mathrm{~km}$ or so, and terminated in Wrightwood in southern California (Sieh, 1978).
} 


\section{Source Model Generation}

The seismic source model is a mathematical representation of the earthquake rupture process. Two types of source models are used in earthquake physics: kinematic models, which prescribe the spatial and temporal evolution of the rupture velocity, the slip, and the slip velocity on the fault, inferred from seismic, geodetic, and geological observations; and dynamic models, which prescribe the fault prestress, fracture energy, and stress drop. An earthquake is nucleated at a point in the model by artificially increasing the prestress above the shear strength. The rupture process is then allowed to evolve dynamically as dictated by an assumed fault friction law. The development of dynamic source models is an active area of research in earthquake source physics (e.g., Guatteri et al., 2003; Harris et al., 2009; Lapusta and Liu 2009; Schmedes et al., 2010; Bizzarri, 2011; DeDontney et al., 2011). While dynamic source models may better characterize earthquake source physics, the theory is more complex and less mature when compared with kinematic source modeling (e.g., the state of stress in the earth and the fault friction law are not known; they are not as well-constrained as kinematic source parameters such as slip). Simulating ground motion reliably by combining dynamic rupture models with seismic-wave propagation (e.g., Graves et al., 2008; Olsen et al., 2008; Olsen et al., 2009) would be hard to achieve near real-time using the present state of knowledge and computational tools. Because of this, kinematic source models are currently more suitable for application to the rapid response estimation problem. Many methods exist for the determination of kinematic fault models from seismic waveform data (e.g., Hartzell et al., 1996; Wald et al., 1996). We use a wavelet transform approach (Ji et al., 2002) that can extract more information about slip heterogeneity by simultaneously considering both the time and frequency characteristics of waveforms. Quick algorithms have been developed to take advantage of real-time seismic observations. Now, a kinematic source model based on teleseismic data is generated by the U.S. National Earthquake Information Center (NEIC), hours after a large earthquake and broadcast through the Internet by the U.S. Geological Survey (2011). In principle, this latency time could be reduced to the subhour timescale, particularly for the analysis of earthquakes using local strong-motion observations.

In Figure 1 we show a finite-source model of the 3 November 2002 magnitude 7.9 earthquake on the Denali fault system in Alaska, estimated using 23 teleseismic $P$ waves, $20 \mathrm{SH}$ waves, $40 \mathrm{GPS}$ vectors, and 4 strong-motion waveforms (Ji et al., 2003). The Denali earthquake initiated as a magnitude 7.1 thrust event on the Susitna Glacier fault, quickly changed to a strike-slip mode of rupture, and propagated southeastward along the Denali fault for $218 \mathrm{~km}$ before jumping to the Totschunda fault and continuing for about $76 \mathrm{~km}$ (Eberhart-Phillips et al., 2003). The surface slip grew slowly to $7.4 \mathrm{~m}$ and then dropped off drastically toward the end of the rupture. The peak slip at depth was about $12 \mathrm{~m}$. Rupture duration was about $94 \mathrm{~s}$.

\section{Ground-Motion Simulation}

After the seismic source model is generated, the next step is to numerically propagate seismic waves through the earth model. Seismologists have created 3D Earth models (Magistrale et al., 1996; Magistrale et al., 2000; Kohler et al., 2003; Süss and Shaw, 2003; Prindle and Tanimoto, 2006; Tape et al., 2009; Ely et al., 2010; Tape et al., 2010; Plesch et al., 2011) of seismic-wave speeds and density, and thanks to the advent of parallel computing now have the ability to study 3D global and regional seismic-wave propagation using approaches based, for instance, on the finite-element and the finite-difference methods (e.g., Heaton et al., 1995; Olsen et al., 1995; Bao et al., 1998; Graves 1998; Akçelik et al., 2003; Komatitsch et al., 2004; Liu et al., 2004; Komatitsch et al., 2010; Komatitsch, 2011; and similar references). Our approach to numerically propagating seismic waves is based on the spectral-element method (Komatitsch and Tromp 1999; Tromp et al., 2008) and accounts for 3D variations of seismic-wave speeds and density, topography and bathymetry, and attenuation. The code for our seismicwave propagation package, SPECFEM3D (V2.0 SESAME),
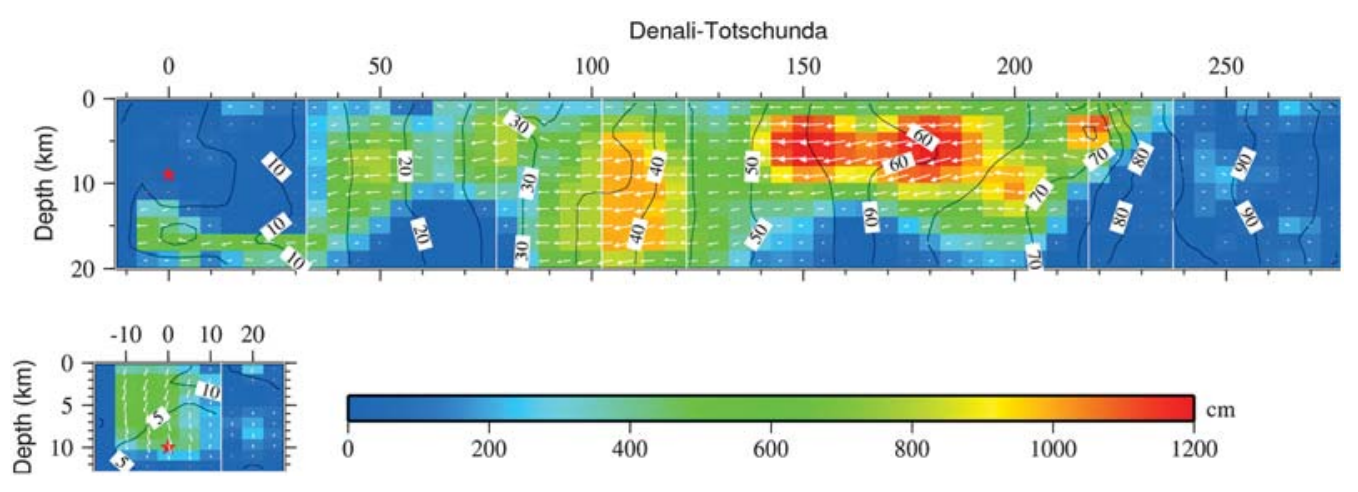

Figure 1. Slip distribution of the 3 November 2002, magnitude 7.9 Denali, Alaska, earthquake constrained by teleseismic body and strong-motion waveforms, as well as GPS vectors. The color scheme reflects the slip amplitude, and contours reflect the rupture initiation time. The hypocenter is indicated by the red star. White arrows denote the slip direction and magnitude. 
is open source (Kellogg, 2011). We use the SCEC Community Velocity Model (CVM-H 11.9) to characterize the seismic-wave speeds, density, topography, bathymetry, and attenuation. This model is based on current research, and incorporates tens of thousands of direct velocity measurements that describe the Los Angeles basin and other structures in southern California (Süss and Shaw, 2003; Plesch et al., 2011). The model includes background crustal tomography (Hauksson, 2000; Lin et al., 2007) enhanced using 3D adjoint waveform methods (Tape et al., 2009), the Moho surface (Plesch et al., 2011), and a teleseismic upper mantle wave speed description (Prindle and Tanimoto 2006). Earlier versions of this wave speed model have been used to reliably model the basin response accurately down to a shortest period of approximately $2 \mathrm{~s}$ (Komatitsch et al., 2004; Liu et al., 2004). A spectral-element mesh of the southern California region, compatible with the wave-speed model, is created using an advanced unstructured mesher, CUBIT, developed by Sandia National Laboratories (2011) and adapted as GeoCUBIT for large-scale geological applications (Casarotti et al., 2008).

An example of a spectral-element simulation is our recreation of an 1857-like magnitude 7.9 earthquake on the southern section of the San Andreas fault. For the computational recreation of this earthquake, we mapped the Denali earthquake source (Fig. 1) on to the San Andreas fault with the hypocenter located at Parkfield. We then computed threecomponent ground motion at 636 sites in southern California (Fig. 2). This simulation is similar to our 2006 simulation
(Krishnan et al., 2006a,b), except that we use the most current wave-speed structure for southern California (Plesch et al., 2011) in conjunction with the CUBIT mesh. Shown in Figure 3 are maps of PGV and displacement (east and north components), low-pass filtered at a corner period of $2 \mathrm{~s}$ according to the wave-speed model and mesh resolution. The solid circles in these maps correspond to the cities shown in Figure 2. The PGV is of the order of $1 \mathrm{~m} / \mathrm{s}$ in the Los Angeles basin, including downtown Los Angeles, and $2 \mathrm{~m} / \mathrm{s}$ in the San Fernando Valley. The corresponding peak displacements are of the order of $1 \mathrm{~m}$ and $2 \mathrm{~m}$, respectively. We used 144 processors on a parallel computer, each with a clock speed of $2.33 \mathrm{GHz}$ and a memory size of $8 \mathrm{~GB}$, for this simulation, interconnected through a QLogic Infiniband switch. The processing time for the 1857-like earthquake simulation was approximately 1 hour.

It is clear that technology exists for a near real-time system that extracts seismic and geodetic data from various data archives in the immediate aftermath of an earthquake, generates the source model rapidly, and simulates threecomponent synthetic waveforms on a dense grid of stations in a region. Somewhat less complex systems have already been implemented for southern California earthquakes (Tromp et al., 2011b) as well as global earthquakes (Tromp et al., 2011a) and are currently operational (Tromp et al., 2010). Both systems are prototype systems implemented to demonstrate proof-of-concept of the near real-time simulation technology. The southern California system collects

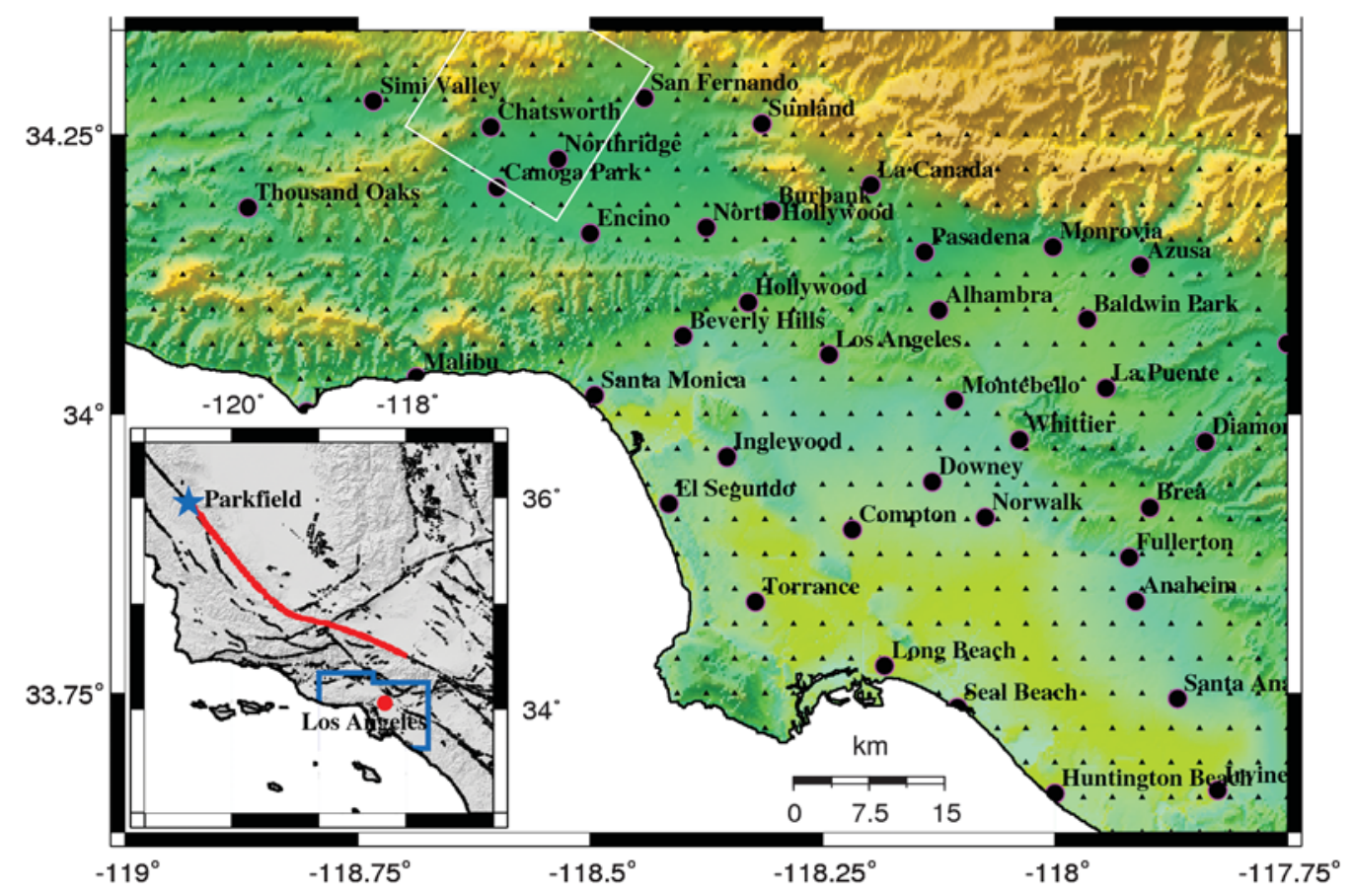

Figure 2. Geographical scope of the 1857-like San Andreas earthquake simulation. (The color scheme reflects topography, with green representing low elevation and yellow representing mountains.) The solid black triangles represent the 636 sites at which seismograms are computed and buildings are analyzed. The white box is the surface projection of the Northridge fault. The red line in the inset is the surface trace of the hypothetical $290 \mathrm{~km}$ rupture of the San Andreas fault that is the primary focus of this study. The area enclosed by the blue polygon denotes the region covered by the 636 sites. 
(a)

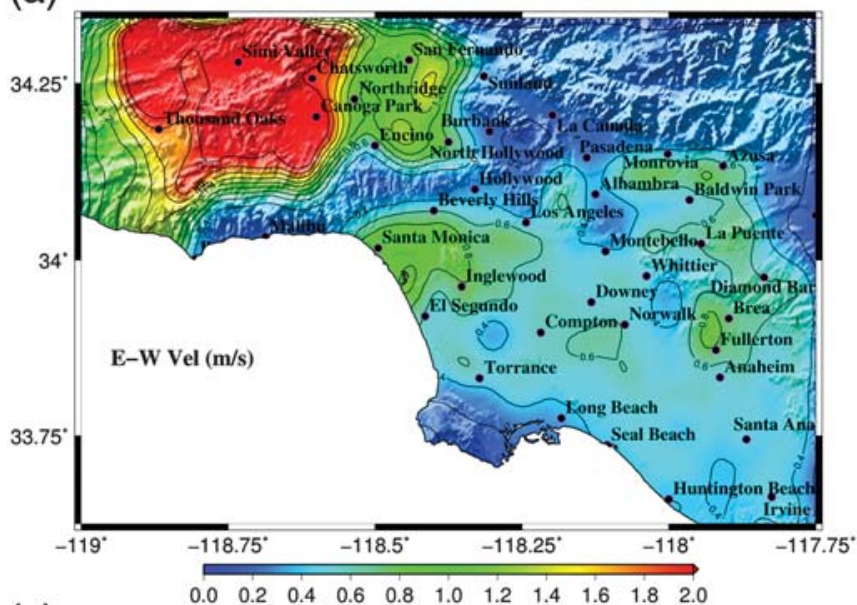

(c)

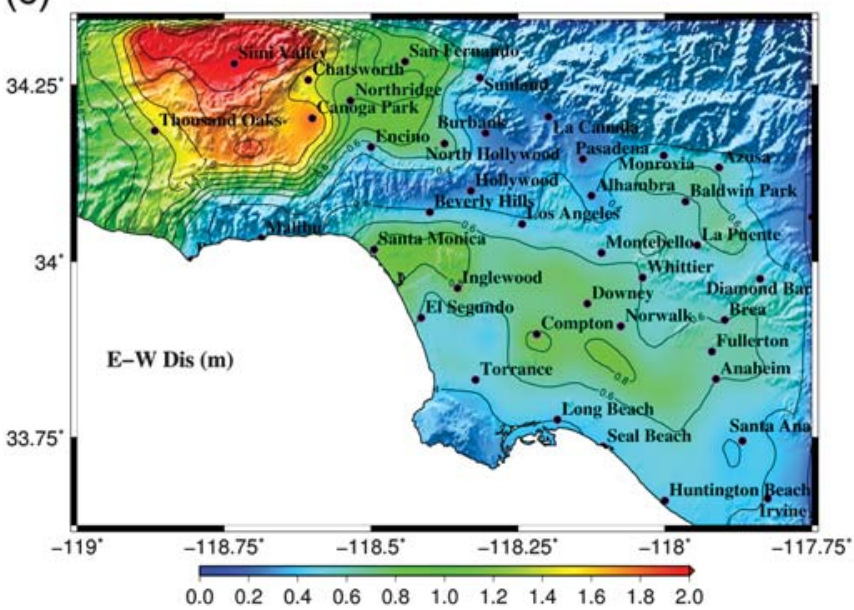

(b)

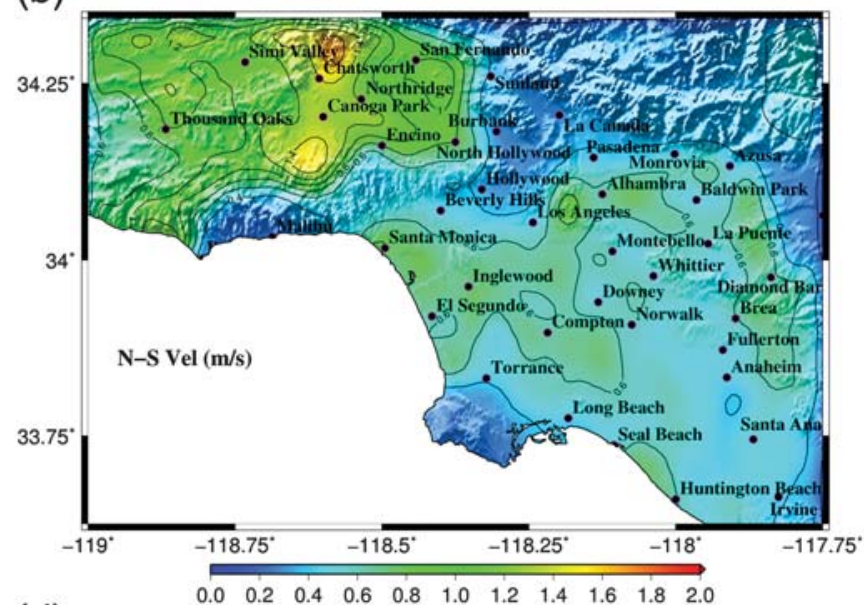

(d)

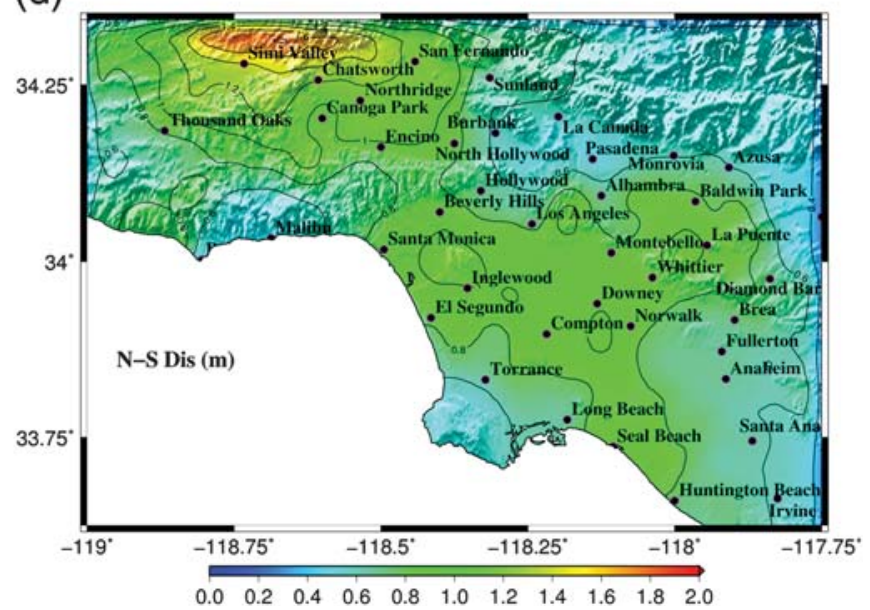

Figure 3. Peak ground velocity and displacement maps of the east and north components of ground motion in the simulated 1857-like San Andreas earthquake.

seismic recordings automatically from the Southern California Seismic Network (SCSN) through the Internet. Using 10 point-source parameters (6 symmetric moment tensor components, 3 location parameters, and the origin time) determined by the SCSN (Clinton et al., 2006), seismic waves are generated and propagated through the SCEC CVM-H southern Calfornia seismic-wave-speed model. Three-component seismic waveforms are computed at sites where seismic stations are located. Synthetic seismograms are compared against the recorded seismograms at periods of $4 \mathrm{~s}$ and longer.

The global earthquake near real-time system accesses the Global Centroidal Moment Tensor (CMT) solution (Dziewonski et al., 1981) for each global earthquake and computes synthetic seismograms in lengths of 100 minutes and 200 minutes for earthquakes with magnitudes less and greater than 7.5, respectively. Seismograms are computed at 1838 stations supported by members of the international Federation of Digital Seismograph Networks. The wave-speed structure used for the simulations is derived from 3D mantle model S362ANI (Kustowski et al., 2008) in conjunction with crustal model Crust2.0 (Bassin et al., 2000), attenuation model QL6
(Durek and Ekström, 1996), and topography and bathymetry model ETOPO1 (Amante and Eakins, 2009).

The near real-time approach outlined here is an extension of these prototype systems wherein the earthquake is characterized by a finite source rather than a point source. This is especially important for large earthquakes for which directivity effects can be significant and the proximity of large asperities (patches of high slip) to a site can greatly influence the nature of ground shaking on a regional scale. For robust damage estimation in engineered structures, such an approach is necessary. The effectiveness of the seismicwave propagation simulations is strongly dictated by the accuracy of the seismic-wave-speed model at various length scales (and how meticulously the finite-element mesh resolves these details) ${ }^{5}$. The ability of the model to reliably

\footnotetext{
${ }^{5}$ Ground-motion simulation validation is an active area of interest in the seismological and engineering communities. For instance, there is an ongoing effort within the Southern California Earthquake Center to develop and implement testing/rating methodologies for synthetic ground motions through a Technical Activity Group comprising ground-motion modelers and engineers.
} 
propagate seismic waves with various wavelengths controls the frequency bandwidth within which the simulated seismic waveforms can be trusted. For instance, the southern California models, SCEC-CVM and SCEC-CVM-H, have been shown to reliably propagate seismic waves of periods $2 \mathrm{~s}$ and longer. This means that we cannot reliably simulate higher frequencies in ground motion; thus, the high-frequency part of the ground motion must be filtered. Because highfrequency content in ground motion can affect the response of low-rise structures significantly, these near real-time seismic waveform simulations cannot be used for rapid estimation of damage to low-rise structures. They can, however, be used to estimate the response of long-period structures (fundamental period nominally greater than $2 \mathrm{~s}$ ) such as the tall buildings considered in this study. ${ }^{6}$ In a past study, we used filtered and unfiltered data from the Chi-Chi and Hokkaido earthquakes to demonstrate that the effect of higherfrequency ground motion (periods $<2 \mathrm{~s}$ ) on the response of these buildings is not substantial (Krishnan et al., 2006a,b) and can be discounted for catastrophe risk assessment and mitigation, and, in this case, rapid damage estimation purposes. As the resolution of the structure of the earth improves, so will our ability to estimate the response of higherfrequency engineered structures.

\section{Structural Response Estimation}

We could use three-component waveforms from the near real-time simulation system at the site of a tall building of interest to perform nonlinear time-history analysis of a model of the building. But this could take anywhere from 5 hours to 24 hours or longer, depending on the extent of plasticity and/or brittle failures (e.g., fracture) occurring in the building under a given three-component ground-motion history. This would seriously delay search and rescue efforts, dramatically affecting the chances of finding people alive in partially or fully collapsed buildings. Here, we take a different approach to postevent structural response estimation, which involves three preevent steps to create a structural response archive.

1. Develop a simplified (idealized) representation scheme for seismic ground-motion waveforms using three parameters to characterize ground-motion frequency content, intensity, and duration.

2. Conduct a parametric nonlinear response history analysis sweep of models of the target tall buildings by varying the parameters of the idealized waveforms; such a suite of analyses can help in identifying damage to these buildings under ground motions with a broad spectrum of features (frequency content, amplitude, and duration).

${ }^{6}$ There are more than 650 buildings taller than 10 stories in southern California that could potentially be studied using synthetic waveforms (Muto and Krishnan, 2011).
3. Create a database of key structural response metrics as a function of ground excitation waveform parameters.

Postevent response estimation for a given ground motion involves determining the closest match of the waveform to one of the idealized waveforms in the database and extracting the corresponding structural response metrics. This computation is rapid and takes only about 10 minutes on a single processor for one structure ground-motion pair. The postearthquake condition of the structure can then be classified as being immediately occupiable (IO), life safe (LS), collapse prevented (CP), red tagged (RT), or collapsed (CO).

\section{Ground-Motion Idealization}

In order to decide upon the most suitable candidate for parameterization (among ground acceleration, velocity, or displacement histories), we turn to the classical analysis of the energy budget in multistory buildings subjected to earthquake excitation (Uang and Bertero, 1988; Uang and Bertero, 1990). Starting from the governing differential equation of motion and integrating all terms with respect to the structural relative displacement vector, $\mathbf{u}$, the equation for energy balance can be written as

$$
E_{k}(t)+E_{\xi}(t)+E_{s}(t)=E_{I}(t)
$$

where $E_{k}(t)$ is the instantaneous kinetic energy of the system, $E_{\xi}(t)$ is the energy dissipated by viscous forces until time $t, E_{s}(t)$ is the recoverable strain energy stored in the system plus the dissipated hysteretic energy until time $t$, and $E_{I}(t)$ is the energy imparted to the system by the input excitation until time $t$, given by

$$
\begin{gathered}
E_{k}(t)=\frac{1}{2} \sum_{i=1}^{N_{f}} m_{i}\left[\dot{u}_{i}+\dot{u}_{g}\right]^{2}, \\
E_{\xi}(t)=\int \mathbf{f}_{\xi}^{T} d \mathbf{u}, \\
E_{s}(t)=\int \mathbf{f}_{\mathbf{s}}^{T} d \mathbf{u}=\sum_{i=1}^{N_{f}} \int f_{s i} d u_{i},
\end{gathered}
$$

and

$$
\begin{aligned}
E_{I}(t) & =\int \sum_{i=1}^{N_{f}} m_{i}\left[\ddot{u}_{i}+\ddot{u}_{g}\right] d u_{g} \\
& =\int \sum_{i=1}^{N_{f}} m_{i} \ddot{u}_{i} d u_{g}+\frac{1}{2} \sum_{i=1}^{N_{f}} m_{i} \dot{u}_{g}^{2} .
\end{aligned}
$$

In equations (2) through (5), $\mathbf{f}_{\xi}$ is the damping force vector, $\mathbf{f}_{\mathrm{s}}$ is the restoring force vector, $m_{i}$ is the mass of floor $i$, and $N_{f}$ is the number of floors in the building. $u_{i}, \dot{u}_{i}$, and $\ddot{u}_{i}$ 
are the displacement, velocity, and acceleration, respectively, of floor $i$ relative to the ground. $u_{g}, \dot{u}_{g}$, and $\ddot{u}_{g}$ are the ground displacement, velocity, and acceleration, respectively. $E_{I}$ is the total work done by all the inertial forces (base shear) on the foundation (displacing through a displacement equal to the ground displacement). In other words, it is the energy imparted to the structure during seismic shaking (Berg and Thomaides, 1960; Goel and Berg, 1968; Mahin and Lin, 1983; Uang and Bertero, 1986). If the input excitation period is much shorter than that of the structure, we have $u_{i} \approx-u_{g}$; as a result, $E_{I} \approx 0$. For the long-period buildings of the kind targeted here, the energy imparted from short-period excitation is small and the peak transient interstory drift ratio (IDR) must consequently be quite small. If the input excitation period is much longer than that of the structure, $u_{i} \approx 0$, and $E_{I} \approx \frac{1}{2} \sum_{i=1}^{N_{f}} m_{i} \dot{u}_{g}^{2}$, that is, the input excitation energy is proportional to the square of the ground velocity. Two facts become clear from this analysis: (1) for long-period structures of the kind targeted here, only long-period ground motion can induce a strong response; (2) this response is extremely sensitive to the PGV. These observations suggest that the best candidate for idealization of ground-motion waveforms is the ground-velocity history in the context of their impact on buildings. An added advantage of choosing to parameterize ground-velocity histories is that, unlike ground-displacement histories, these waveforms are devoid of static offsets. In the context of tall building response, they can be adequately characterized by three features: the frequency content of the waveform (period of predominant shaking), the PGV, and the duration represented by the number of cycles. It should be noted that the energy balance analysis is not appropriate for excitation velocities that are extreme; conservation of momentum may be more applicable in such cases. However, PGV from earthquakes seldom exceeds $2.5 \mathrm{~m} / \mathrm{s}$, and energy balance would generally be applicable.

Here, ground-velocity waveforms are idealized as triangular (sawtoothlike) wave trains as shown in Figure 4b. This ground-motion representation scheme was first used by Hall et al. (1995) to study the effects of near-source ground motion on tall building response. The displacement history in this representation closely mimics the displacement pulse that would result from the rupture of a penny-shaped crack on a fault surface (point-source) in the vicinity of the crack (Clough and Penzien, 1993). Although a single cycle is shown in the figure, multicycle extensions with identical period and amplitude are also used to represent long-duration groundmotion waveforms. The acceleration waveform corresponding to this velocity history is a rectangular wave train (Fig. 4c), while the displacement is a one-sided parabolic wave train (Fig. 4a). The one-sided nature of the displacement should not be of concern. For multicycle excitation, displacement is cyclic but always has a positive sign. This is an artifact of the idealization scheme, mathematically equivalent to shifting the origin of the frame of reference, and should have little or no effect on the dynamics of the structure.

Three parameters are used to characterize the ground velocity waveform: period $T$, amplitude $P G V$, and number of cycles $N$. The ability of this ground-motion representation to accurately emulate the true seismic ground-motion waveforms for impacts on the buildings of interest must be ensured. Toward this end, the best-fitting single-cycle idealized waveform from a suite of idealized waveforms to the strong component of 18 near-source records (velocity histories) is determined using the least absolute deviation method $\left(L_{1}\right.$ norm). The idealized waveform suite comprises waveforms with periods varying between $0.5 \mathrm{~s}$ and $6.0 \mathrm{~s}$ at $0.25 \mathrm{~s}$ intervals, $P G V$ varying between $0.125 \mathrm{~m} / \mathrm{s}$ and $2.5 \mathrm{~m} / \mathrm{s}$ at $0.125 \mathrm{~m} / \mathrm{s}$ intervals, and the number of cycles $N$ varying from 1 to 5 . The three intervals are chosen judiciously (not calibrated), commensurate with the computational resources at hand. The near-source earthquake records are from the 1971 San Fernando, 1978 Iran, 1979 Imperial Valley, 1987 Superstition Hills, 1989 Loma Prieta, 1992 Cape Mendocino, 1992 Landers, 1994 Northridge, 1995 Kobe, and 1999 Chi-Chi earthquakes. The idealized waveform fits for four cases are shown in Figure 5. Bestfitting two-, three-, four-, and five-cycle waveforms are shown as well. These are not utilized in the forthcoming analysis because all the records have a prominent near-source pulse that is likely to dominate the structural response. They are, however, used in characterizing ordinary multicycle
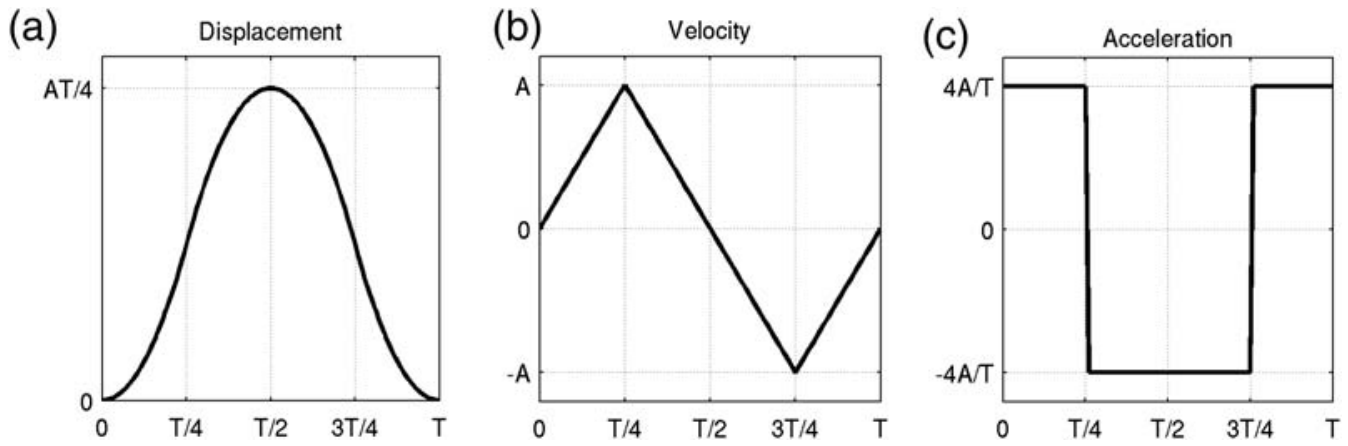

Figure 4. Waveforms for the (a) displacement, (b) velocity, and (c) acceleration of the idealized pulses used as input ground motions. 

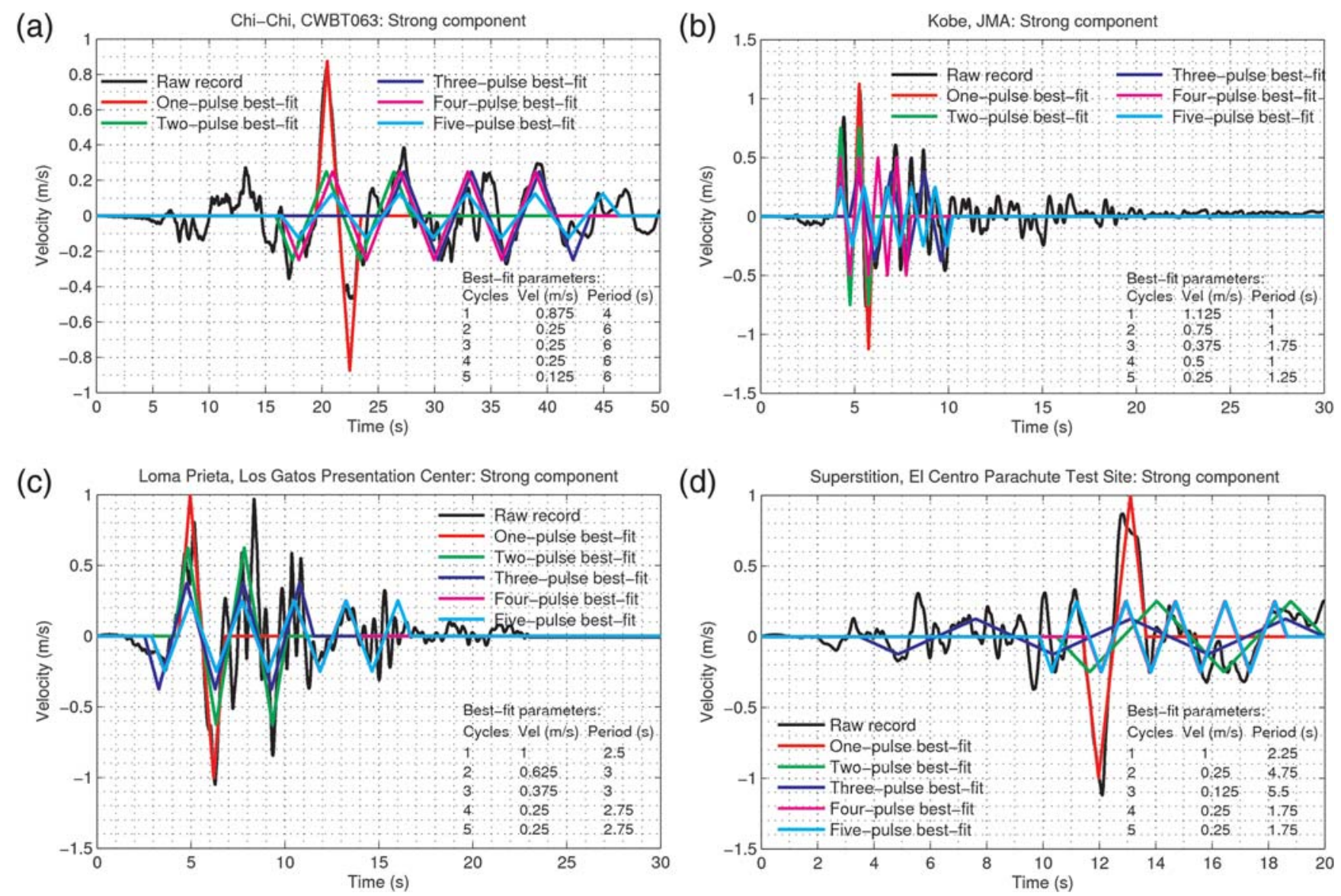

Figure 5. Near-source ground-motion records from the Chi-Chi (Taiwan), Kobe (Japan), Loma Prieta (California), and Superstition Hills (California) earthquakes. Also shown are the idealized one-, two-, three-, four-, and five-cycle sawtooth waveforms with the least absolute deviation $\left(L_{1}\right.$ norm) from the corresponding record.

ground motion. The fits for the remaining 14 cases can be found in Krishnan and Muto (2011).

To ensure the suitability of the ground-motion idealization scheme for application to the rapid estimation of structural response, we analyze the FRAME3D model of an existing 18-story office building under the 18 near-source records and compare the responses against that under the best-fitting idealized one-cycle sawtooth waveform. This building is located within five miles of the epicenter of the 1994 Northridge earthquake. An isometric view of its FRAME3D model is shown in Figure 6a. It was designed according to the 1982 Uniform Building Code (UBC) and completed in 1986. The height of the building above

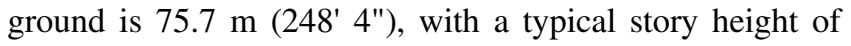

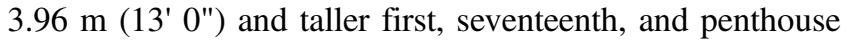
stories. The lateral force-resisting system consists of two-bay welded steel moment-frames (MF), two apiece in either principal direction of the structure as shown in Figure 6b. The location of the north frame one bay inside of the perimeter gives rise to some torsional eccentricity. Many MF beamcolumn connections in the building fractured during the Northridge earthquake, and the building has been extensively investigated since then by engineering research groups (SAC, 1995; Chi et al., 1998; Carlson, 1999). Fundamental periods, computed assuming $100 \%$ dead load and $30 \%$ live load contribution to the mass, are $4.52 \mathrm{~s}$ (X-translation), $4.26 \mathrm{~s}$ (Y-translation), and $2.69 \mathrm{~s}$ (torsion). The corresponding second-mode periods are $1.64 \mathrm{~s}$ (X-translation), $1.59 \mathrm{~s}$ (Y-translation), and $1.19 \mathrm{~s}$ (torsion). The FRAME3D model of the building uses panel zone elements and elastofiber elements to model the structural frame, and plane stress elements to represent the floor diaphragms. The story masses are lumped at the column locations based on plan tributary area. Composite action due to the connection between the floor slabs and the MF beams is not considered. A rigid foundation is assumed, with the base of all columns fixed. Soil-structure interaction is not included. To model brittle failure of the welded connections, a fracture strain level is prescribed for the fibers comprising the nonlinear end segments of the beam elements. When this strain level is exceeded for a given fiber, it is considered to be fractured and can no longer resist tensile forces, though it can resist compressive forces. Fracture strain values for each elastofiber element are randomly assigned according to a user-defined 
(a)

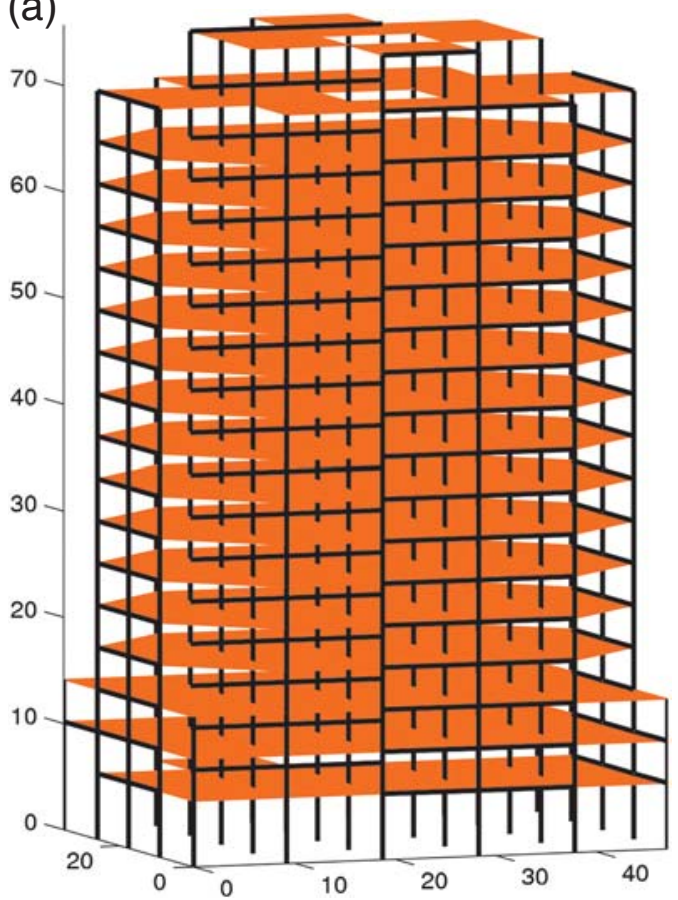

(b)

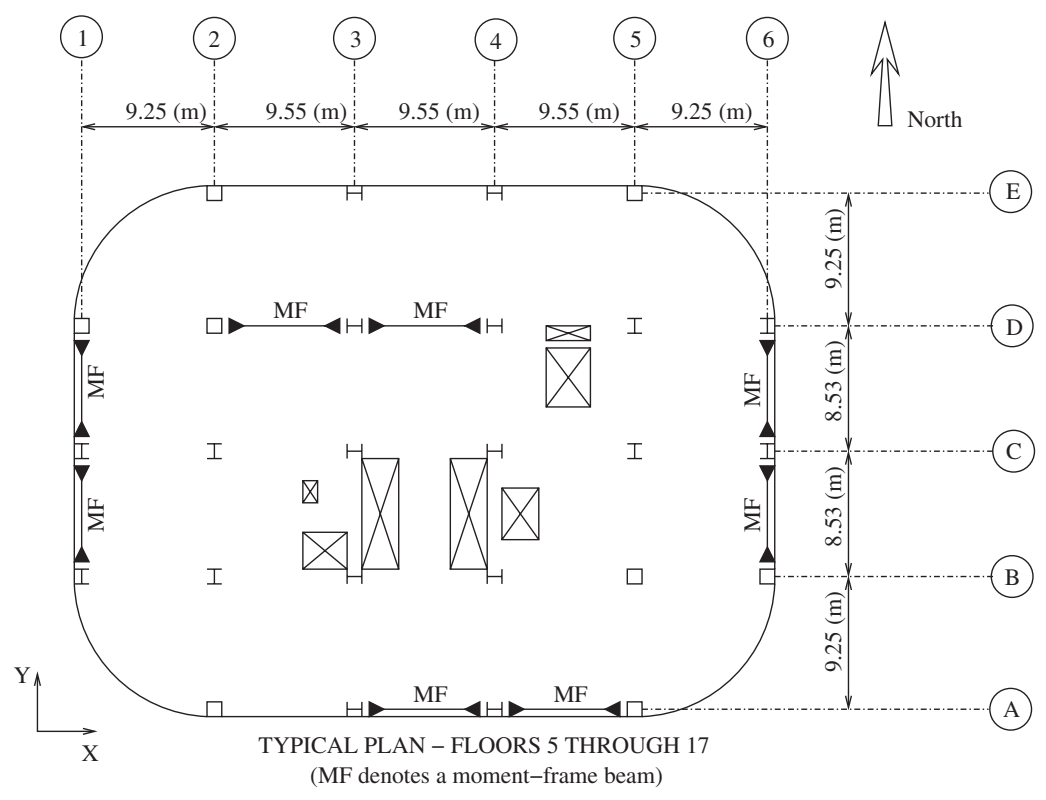

Figure 6. Structural model of the 18-story steel MF building, designed using the 1982 Uniform Building Code (UBC): (a) isometric view; (b) plan view of a typical floor of the building showing the location of columns and MF beams.

probability distribution (beam bottom flanges: probability is $20 \%$ that the fracture strain is $0.9 \epsilon_{y} ; 20 \%$ that it is $2.0 \epsilon_{y} ; 20 \%$ that it is $5.0 \epsilon_{y} ; 20 \%$ that it is $15.0 \epsilon_{y}$; and $20 \%$ that it is $40.0 \epsilon_{y}$; beam top-flanges and webs: probability is $30 \%$ that the fracture strain is $10.0 \epsilon_{y} ; 30 \%$ that it is $20.0 \epsilon_{y} ; 20 \%$ that it is $40.0 \epsilon_{y}$; and $20 \%$ that it is $80.0 \epsilon_{y}$; column flange and web fibers: fracture strains are assumed far greater than the rupture strain, thus precluding the occurrence of fractures). Greater details of the structural modeling are provided in Krishnan and Muto (2011).

The FRAME3D model of the existing building with susceptible connections is analyzed under the 18 threecomponent near-source records. The strong component of ground motion is oriented in the building X-direction. The peak transient IDR, which is the peak value for all stories of the relative displacement between the top and bottom of a story normalized by its height, is used as a measure of structural performance. It is a good indicator of damage to both structural elements (plasticity and fracture) as well as many types of nonstructural elements. The same model is also analyzed under the one-component best-fitting singlecycle idealized waveforms. Shown in Figure 7 is the comparison of the profiles of peak transient IDR over the building height under the four actual and idealized motions of Figure 5. The consistently good match of the profiles indicates that the particular idealization adopted here to characterize the ground motion can be effectively used for rapid estimation of the response of this building. The peak values
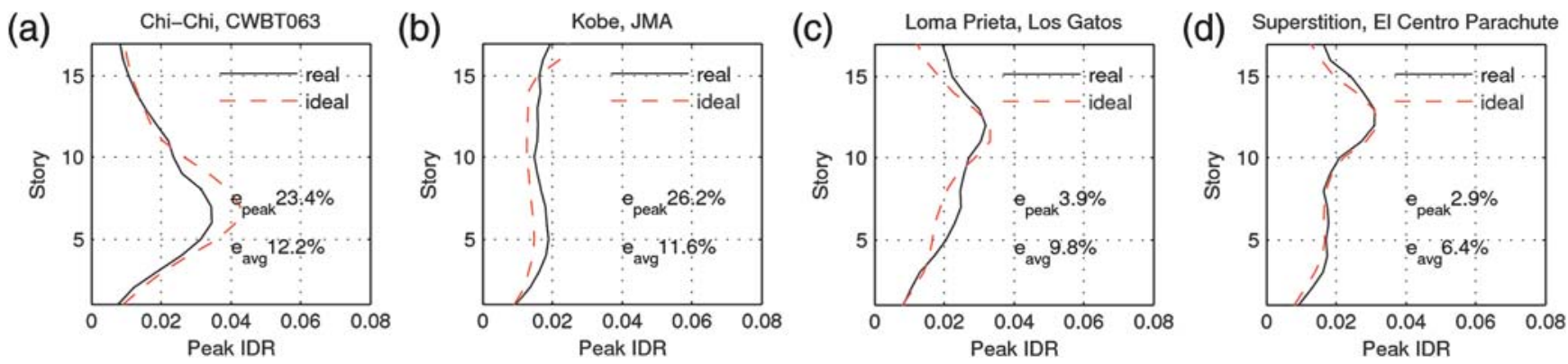

Figure 7. Comparison of peak transient IDR profile over building height computed using real records (earthquake records from Chi-Chi, Taiwan; Kobe, Japan; Loma Prieta, California; and Superstition Hills, California) against that computed using the best-fit idealized one-cycle sawtooth waveform. 
(a)

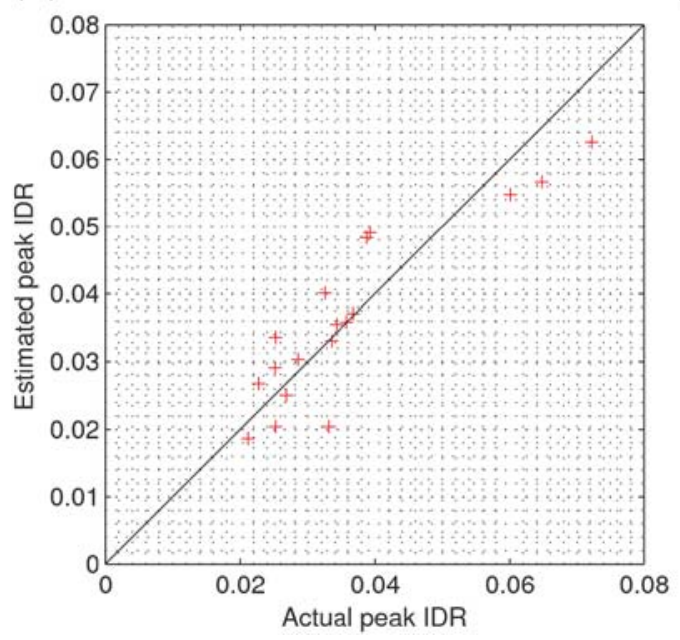

(b)

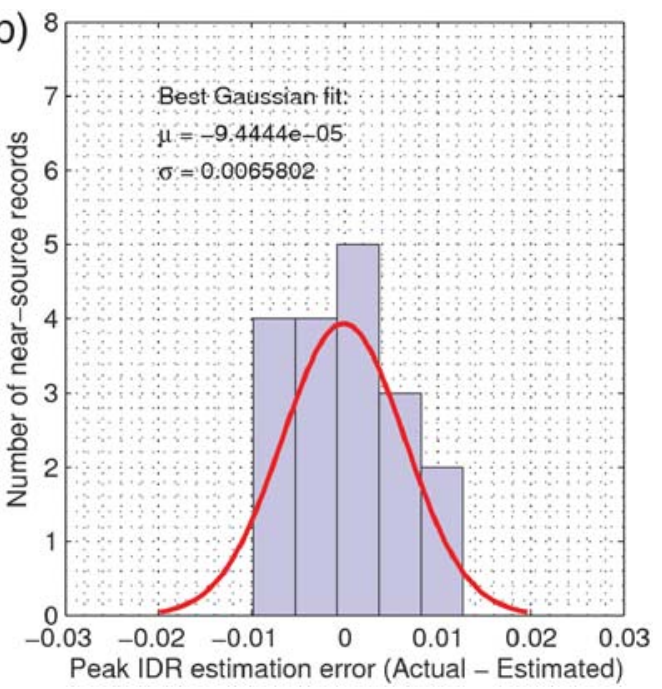

Figure 8. (a) Peak transient IDR in the existing building model with susceptible connections computed using the near-source records plotted against that computed using best-fit idealized one-cycle sawtooth waveforms. The diagonal line represents identical results from the two analyses. (b) Histogram of the error in determining the peak transient IDR from the idealized waveform as opposed to the actual record. The best-fit Gaussian is also shown.

of IDR from the two sets of analysis for all 18 near-source records are compared against each other, and the errors are quantified in Figure 8. The IDR errors have a Gaussian mean of -0.0000944 and a standard deviation of 0.00658 , small enough for rapid estimation purposes.

\section{Structural Response Database}

For rapid estimation purposes, we store the structural responses of the existing building under the idealized sawtooth ground-motion waveform suite introduced in the GroundMotion Idealization section $(0.5 \mathrm{~s} \leq T \leq 6.0 \mathrm{~s}, 0.125 \mathrm{~m} / \mathrm{s}$ $\leq P G V \leq 2.500 \mathrm{~m} / \mathrm{s}$, and $1 \leq N \leq 5$ ). The one-component ground motion is applied independently in the two principal directions of the building. The key response metrics computed and stored in the database include the peak transient IDR and its location over the building height; the peak residual IDR and its location; permanent roof drift (or tilt) following seismic shaking; plastic rotations in beams, columns, and joints (panel zones); and locations of fractures in the model with fracture-susceptible connections. The peak residual IDR is computed by low-pass filtering the IDR histories and averaging the points within a 5-s time-window that has the lowest variance of all such time-windows in the record. A two-pass Butterworth filter with a corner at $10 \mathrm{~s}$ is employed. A similar approach is adopted for computing the permanent roof drift, which is the roof residual displacement normalized by building height. The penthouse is excluded from the peak transient IDR calculations. It has a much smaller floor plate than the typical floor of the two buildings. Moreover, the primary MFs are terminated at the seventeenth story.

The following maps are generated to help dissect the structural response as a function of the ground-motion features (Krishnan and Muto, 2011).
1. Color maps with contours of peak transient IDR (and its story location) on the $T-P G V$ plane, one map for each $N$.

2. Peak transient IDR (and its story location) maps on the $P G D-P G V$ plane, one map for each $N$.

3. Peak residual IDR (and its story location) maps on the $T-P G V$ plane, one map for each $N$; peak residual IDR is the maximum irrecoverable kinking within any story of the building. Its magnitude is indicative of the degree of nonlinearity experienced by the structure during the earthquake.

4. Permanent roof drift (roof residual displacement normalized by building height) maps on the $T-P G V$ plane, one map for each $N$.

Shown in Figure 9 are examples of each of these maps for the existing building model with susceptible and perfect connections subjected to idealized one-cycle sawtooth ground motion in the X-direction. For these contour maps, the data from the parametric analysis are interpolated on a fine parameter grid using a triangle-based linear interpolation technique and filtered using a disk-shaped correlation filter to smooth sharp transitions in the contours. Also plotted on the peak transient IDR maps are contours corresponding to upper limits on IDR for immediate occupancy (IO; IDR $=0.007$ ), life-safety $(\mathrm{LS}$; IDR $=0.025)$, and collapse prevention $(\mathrm{CP}$; IDR $=0.05)$ performance levels. These performance levels are adopted from FEMA (2000). Contours corresponding to peak transient IDRs of 0.075 (red tagged, RT) and 0.100 (collapsed, $\mathrm{CO}$ ) are shown as well. Gravity-driven progressive collapse invariably takes hold of our numerical models beyond peak transient IDRs of 0.100. However, because our models do not include degradation due to local flange buckling, we believe the probability of collapse in real-world buildings to be significant beyond peak transient IDR values of 0.075 . The structural performance levels are summarized in Table 1. 
(a)

a) Existing building (susceptible connections): One-cycle $X$ excitation Peak IDR

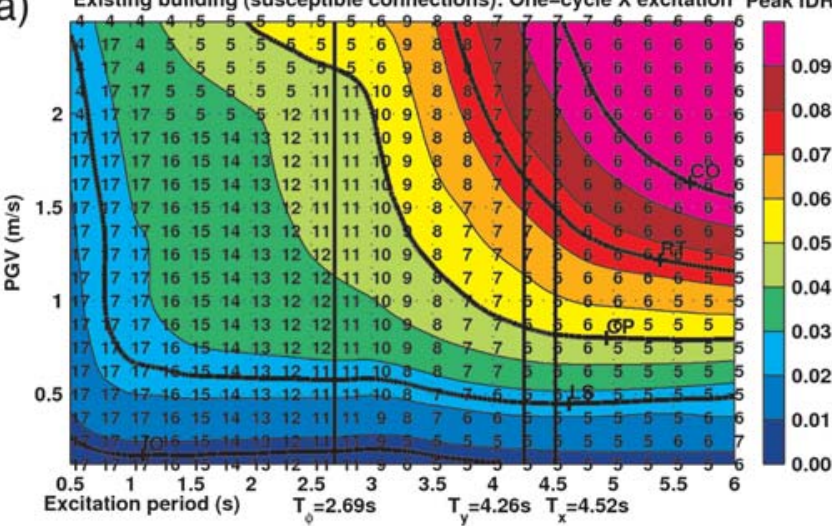

(C) Existing building (susceptible connections): One-cycle $X$ excitationPeak RIDR

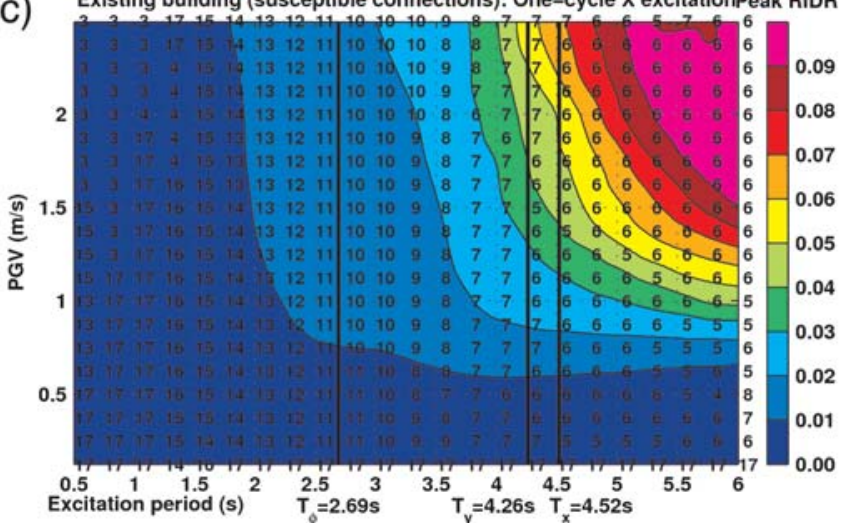

(e) Existing building (susceptible connections): One-cycle $X$ excitation Bldg. Tilt

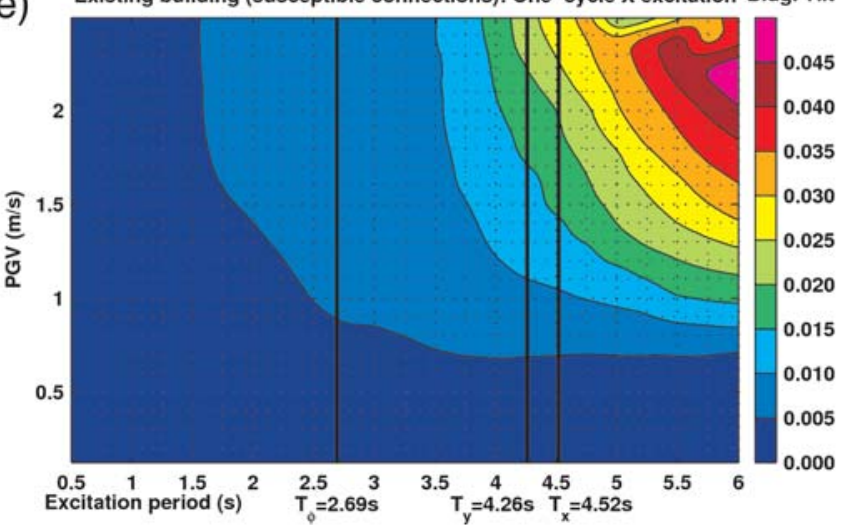

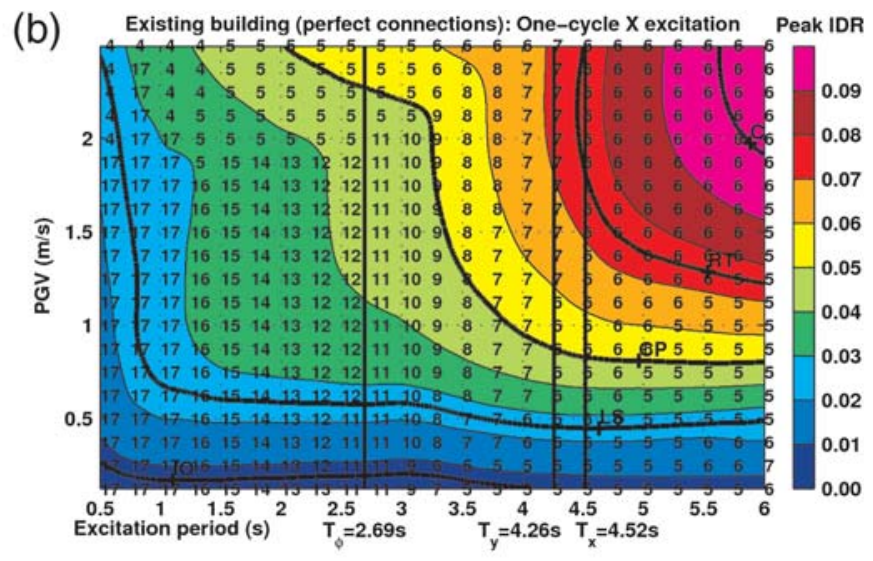
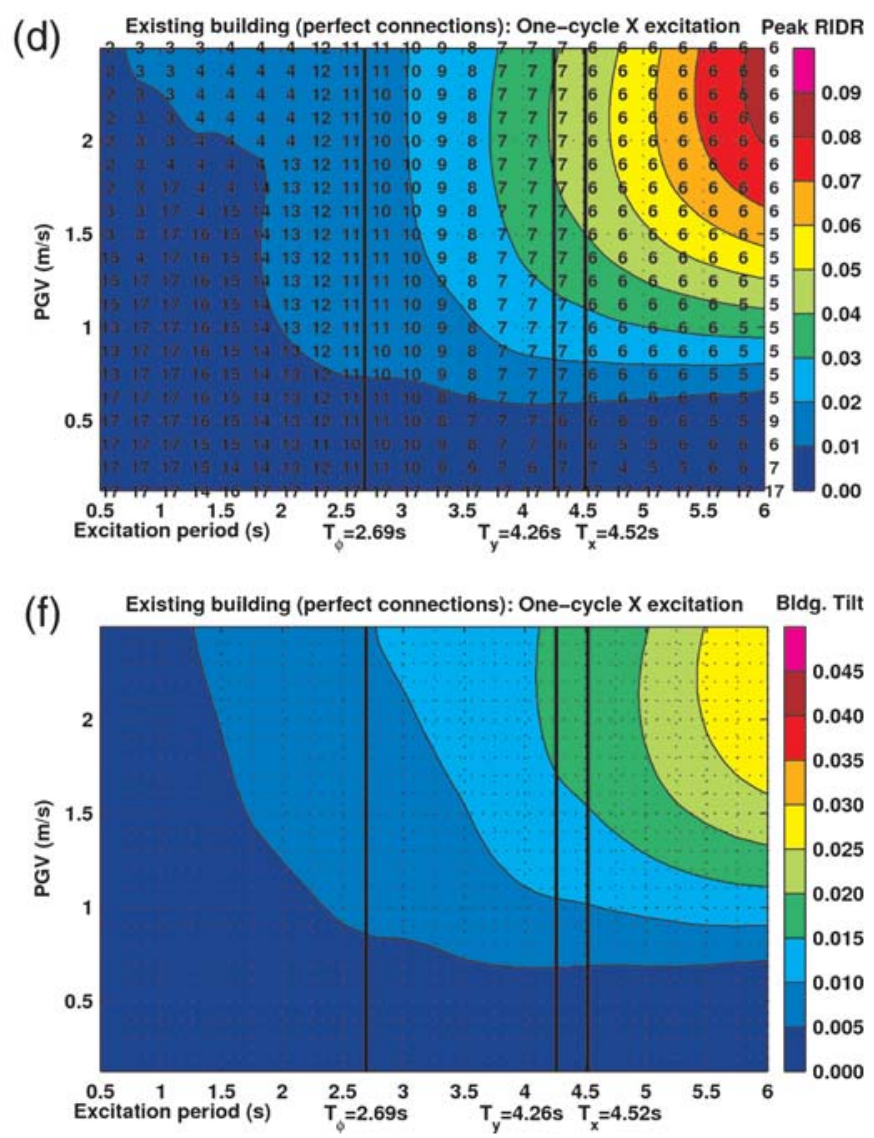

Figure 9. (a,b) Peak transient IDR, (c,d) peak residual IDR, and (e,f) permanent roof drift maps for the 18-story building with susceptible and perfect connections as a function of idealized sawtooth waveform excitation parameters, period $T$ and $P G V$. The one-component onecycle ground motion is applied in the building X-direction. The story location where the peak occurs is labeled at each of the $460[T, P G V]$ combinations for which analyses were performed. Contours corresponding to empirical performance levels of immediate occupancy (IO), life-safety (LS), collapse prevention (CP), red tagged (RT), and collapsed (CO), are shown in bold. The principal direction fundamental periods of the building are indicated for reference.

\section{Rapid Estimation of Response}

In the immediate aftermath of a large earthquake, the near real-time ground-motion simulation system will be used to generate a synthetic ground-motion waveform at the site of interest. The three-component waveform will then be suitably rotated to determine the time histories in the two principal directions of the building. Using the $L_{1}$ norm, the best-fitting idealized sawtooth waveform to either component is determined. The structural response can then simply be read off from the response maps (e.g., Fig. 9) or extracted from the response database using a table-lookup approach, thus bypassing time-history analyses using recorded motions and building models.

To verify the ability of such an approach to predict tall building damage regionally, the existing building (perfect 
Table 1

Structural Performance Levels, Associated Response Metrics, and Postearthquake Damage States*

\begin{tabular}{|c|c|c|c|c|}
\hline \multirow[b]{2}{*}{ Number } & \multicolumn{2}{|r|}{ Performance Level } & \multirow[b]{2}{*}{$\begin{array}{l}\text { Transient IDR } \\
\text { Upper Limit }\end{array}$} & \multirow[b]{2}{*}{ Postearthquake Damage State } \\
\hline & Label & Description & & \\
\hline 1 & IO & Immediate occupancy & 0.007 & $\begin{array}{l}\text { Very light/limited structural damage } \\
\text { No permanent drift, minor repairs } \\
\text { Immediately occupiable }\end{array}$ \\
\hline 2 & LS & Life-safety & 0.025 & $\begin{array}{l}\text { Moderate damage, but structure retains a margin against partial collapse } \\
1 \% \text { residual drift, structure repairable, but may be economically impractical } \\
\text { Building likely to be shut down for repairs }\end{array}$ \\
\hline 3 & $\mathrm{CP}$ & Collapse prevention & 0.050 & $\begin{array}{l}\text { Severe damage, on the verge of partial collapse } \\
5 \% \text { residual drift, structure may be irrepairable } \\
\text { Building may need to be demolished }\end{array}$ \\
\hline 4 & RT & Red tagged & 0.075 & $\begin{array}{l}\text { Partial collapse may have occurred } \\
\text { Building is red tagged; needs to be demolished }\end{array}$ \\
\hline 5 & $\mathrm{CO}$ & Collapsed & 0.100 & $\begin{array}{l}\text { Partial collapse near-certain; complete collapse likely } \\
\text { Near-certain complete collapse beyond IDR of } 0.100\end{array}$ \\
\hline
\end{tabular}

*Taken in part from FEMA (2000).

connections) model is analyzed under the 636 three-component synthetic motions (low-pass filtered at a corner at $2 \mathrm{~s}$ ) from the simulated 1857-like San Andreas fault earthquake described in the Ground-Motion Simulation section. The $\mathrm{X}$-direction of the building is oriented in the geographical east direction. The peak transient IDR at all locations is shown on a regional map in Figure 10a.

The one-, two-, three-, four-, and five-cycle idealized waveforms that best fit the two horizontal components of the 636 three-component ground-motion histories are first determined independently of each other. The $L_{1}$ norm (least absolute deviation) is used for this optimization (see Portnoy and Koenker, 1997 and references therein). Peak transient IDR under each of the five waveforms in either direction is extracted from the corresponding structural response database. For the east component idealization, the database corresponding to the response of the existing building (perfect connections) to X-direction excitation is used. For the north component idealization, the database corresponding to the response of the existing building (perfect connections) to Y-direction excitation is used. In the first attempt, the peak transient IDR at each location is estimated as the maximum of these 10 IDRs. Typical buildings are provided with lateral force-resisting systems in two mutually orthogonal directions to counter the two horizontal components of ground shaking. For rapid estimation purposes, the responses in the two directions are assumed to be independent. Needless to say, torsional effects cannot be accurately captured by this estimation procedure.

The results of the estimation are given in Figure 10. This direct approach to response estimation results in underestimation at many locations. The Gaussian mean estimation error in the IDR is 0.0086 and the standard deviation is 0.0137 (Fig. 10c). It should be noted that the peak transient IDR is capped at 0.10 (i.e., if peak IDR exceeds 0.10 , it is reset to
0.10 for this mapping) to avoid isolated occurrences of collapse (with very large IDRs) from dominating the landscape. ${ }^{7}$ This is a reasonable thing to do because once peak transient IDR has crossed 0.10, it is irrelevant what the actual value is; the building should be deemed collapsed. Five fragility curves, characterizing the cumulative probability of exceedance of the peak IDR limits corresponding to the IO, LS, CP, RT, and CO performance levels as a function of $\mathrm{PGV}$, are generated using log-normal fits to the synthetic data at the 636 southern Californian sites. Maximum likelihood estimation is used to determine the mean and the standard deviation of the lognormal distributions. Fragilities are computed using both actual and estimated IDRs and compared in Figure 10d. The underestimation of peak IDR using the direct approach results in lower probability of exceedance of each performance limit at a given PGV than that derived using actual IDRs.

The lower estimates for IDR from the direct approach occur at locations where the strong ground-motion component has one big pulse followed by a trailing wave train with somewhat lower, but not insignificant, amplitudes. For example, consider the hypothetical velocity history shown in Figure 11. It has one very strong pulse followed by two trailing pulses that are relatively weaker, yet quite strong. The one-cycle best-fit idealization has an amplitude of $1.625 \mathrm{~m} / \mathrm{s}$, while the three-cycle best-fit idealization has an amplitude of $1.25 \mathrm{~m} / \mathrm{s}$ (the amplitudes differ by a moderate $0.375 \mathrm{~m} / \mathrm{s}$ ). This implies that the waveform has one

\footnotetext{
${ }^{7}$ When collapse occurs in the simulation, the peak transient IDR can become very large (gravity-driven progressive collapse invariably takes hold of our numerical models beyond peak transient IDRs of 0.10 ). The interpolation with smoothing then results in large smeared blotches centered on isolated locations where collapse occurs, indicating collapse at the adjacent sites even though collapse has not occurred there. Capping the peak transient IDR to 0.10 makes the red blotches less prominent and paints a more realistic picture of the regional response.
} 

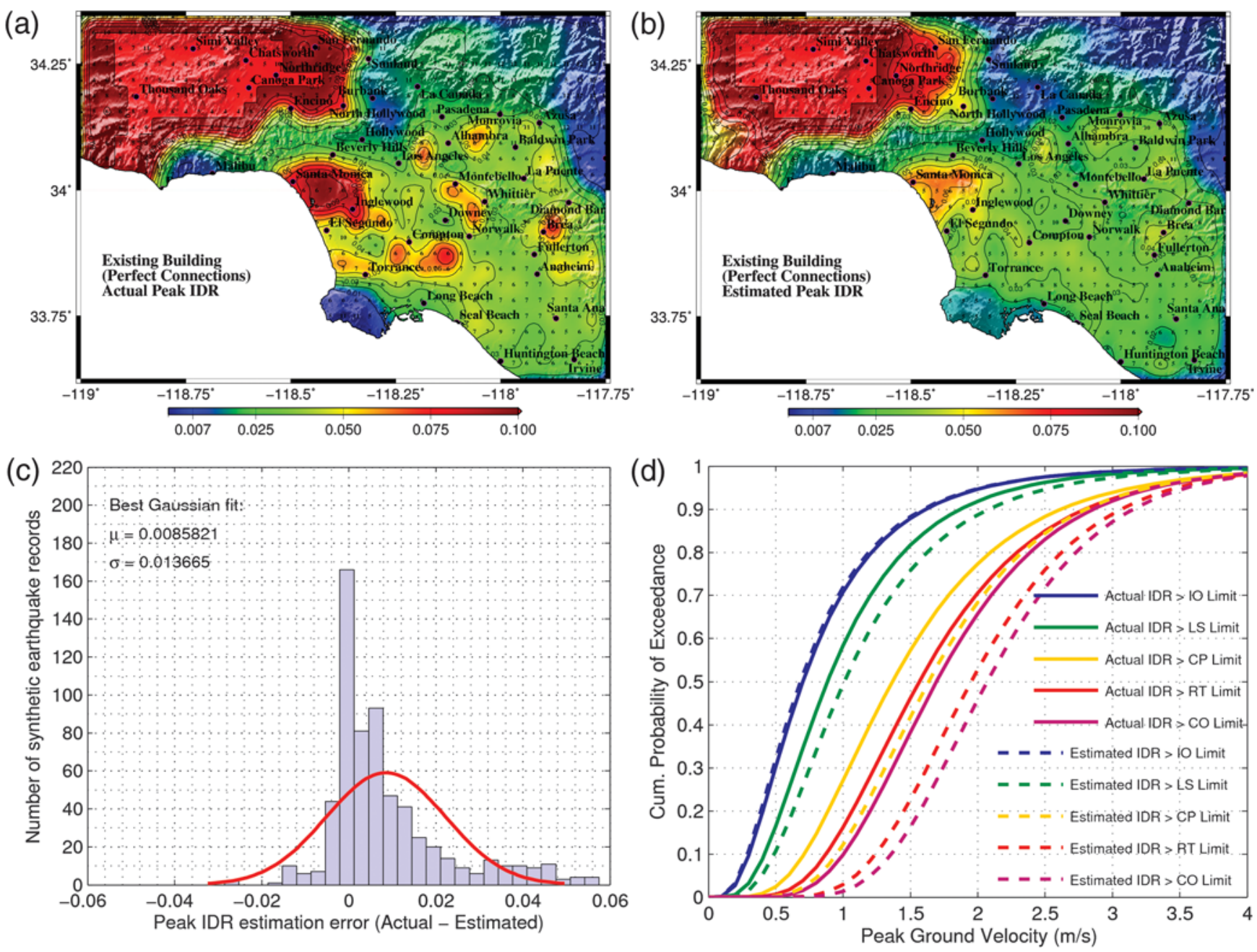

Figure 10. (a) Map of peak transient IDR in the building (perfect connections) computed using synthetic three-component waveforms at 636 sites from the 1857-like San Andreas earthquake simulation. (b) The corresponding map of estimated peak transient IDR computed using the best-fitting idealized sawtooth waveforms to the horizontal components of the synthetic motion. (c) Histogram of the estimation error and the best Gaussian fit. (d) Comparison of fragilities determined using computed responses in (a) and the estimated responses in (b). These are results obtained using the direct rapid estimation approach. Note: Peak transient IDR is capped at 0.10.

pulse with a nominal amplitude of $1.625 \mathrm{~m} / \mathrm{s}$ and two trailing pulses whose average amplitude $v_{\text {ave }}$ can be computed by solving $\left(2 \cdot v_{\text {ave }}+1.625\right) / 3=1.25$. In this case, the two trailing pulses are quite intense, and their average nominal amplitude works out to $1.0625 \mathrm{~m} / \mathrm{s}$. These pulses can place significant additional demands on the structure, especially if the leading pulse causes the building to yield. The best-fit one-cycle idealization captures the first peak well, but misses out on the trailing two pulses, whose effects on building response are then left out, resulting in response underestimation. The best-fit three-cycle idealization has an amplitude that is closer to the amplitude of the two trailing pulses. As a result, the effect of the strong first peak is not captured, once again resulting in underestimation. A modified approach to estimating the peak transient IDR becomes necessary for such cases. Given the strength of the largest pulse, it may be assumed that the entire transient interstory drift from this pulse is permanent (plastic) in nature. If the story location of the peak transient IDR under the three-cycle idealization matches that under the one-cycle idealization, the peak transient IDR under the true waveform can be estimated as the peak transient IDR from the first strong cycle, plus the peak transient IDR under the trailing twocycle excitation. As shown in the figure, the amplitude of the best-fit to the two trailing pulses can be deduced to be $\left(3 \cdot P G V_{3}-1 \cdot P G V_{1}\right) /(3-1)$. Here, $P G V_{3}$ is the amplitude of the three-cycle best-fitting waveform and $P G V_{1}$ is the amplitude of the one-cycle best-fitting waveform.

The outline of the modified rapid estimation approach is as follows (the first two steps constitute the direct approach).

1. The best-fitting one-, two-, three-, four-, and five-cycle waveforms to the two horizontal components of the measured or synthetic record are determined.

2. The structure response database is queried for the peak transient IDR under each of the 10 best-fit idealized 

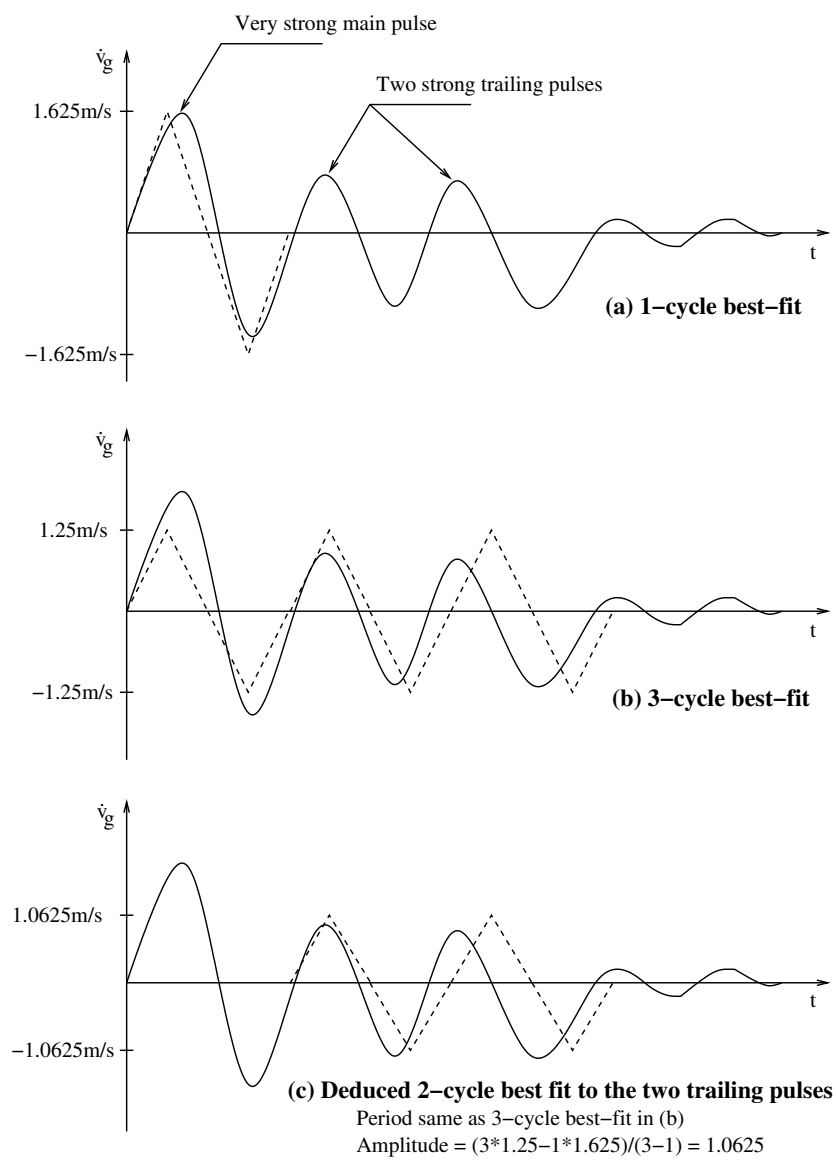

Estimated peak transient IDR $=[$ Peak transient IDR under 1-cycle best-fit in (a) + Peak transient IDR under the deduced 2-cycle best-fit to the two trailing pulses in (c)]

Figure 11. Hypothetical velocity history with one very strong pulse followed by two weaker, yet quite significant, trailing pulses. Neither the best-fit one-cycle pulse nor the best-fit three-cycle pulse is able to capture the structural response effectively. A modified approach to estimate the peak transient IDR is employed in such cases. It involves deducing the amplitude of the best-fit two-cycle waveform to the two trailing pulses using the best-fit one-cycle and three-cycle waveforms. The peak transient IDR is then estimated as the sum of the peak transient IDRs under the best-fit one-cycle waveform and the best-fitting two-cycle waveform to the two trailing pulses.

waveforms (1-5 cycles and two components), with due consideration to the building orientation relative to the azimuth of the two ground-motion components. In the San Andreas example, the X-direction database is used to estimate the peak transient IDR under the east component idealizations, while the Y-direction database is used for IDR estimation under the north component idealizations. The peak transient IDR is the maximum of the 10 IDRs resulting from the database queries, with the following exceptions.

3. The $P G V$ of the five-cycle $(I=5)$ idealized waveform is compared against the $P G V$ of the one-cycle, two-cycle, three-cycle, and four-cycle $(J=1,2,3,4)$ waveforms. If, for any $J$, the difference is $0.25 \mathrm{~m} / \mathrm{s}$ or $0.375 \mathrm{~m} / \mathrm{s}$, then the response is estimated by superposing the response

under the $J$-cycle idealization and the best-fitting waveform for the trailing $[I-J]$-cycle waveform. The amplitude of the trailing $[I-J]$-cycle waveform is taken to be $\left(I \cdot P G V_{I}-J \cdot P G V_{J}\right) /(I-J)$, and its period is taken to be identical to the original $I$-cycle best-fit. Here, $P G V_{I}$ is the amplitude of the $I$-cycle best-fitting waveform, and $P G V_{J}$ is the amplitude of the $J$-cycle best-fitting waveform. The process is repeated for $I=4,3,2$, with $J$ varying from 1 to $I-1$. The largest IDR that results from these computations is taken to be the best estimate of structural response to the ground-motion waveform under consideration.

The peak transient IDR response of the existing building (perfect connections) under the synthetic ground motion from the 1857-like San Andreas earthquake at each of the 636 analysis sites is estimated using this procedure. The results are shown in Figure 12b for convenient comparison against the actual values shown in Figure 12a. The errors are quantified in the histogram, and its best-fit Gaussian distribution is shown in Figure 12c. The distribution has a mean of 0.0044 and a standard deviation of 0.012 . To understand the effectiveness of the rapid estimation procedure, the IDRs must be related to useful damage measures or performance levels that can be used in the decision-making process for disaster response. Recall that the IDR limits for the IO, LS, CP, RT, and CO performance levels (Table 1) are $0.007,0.025,0.05,0.075$, and 0.100, respectively. Clearly, the standard deviation of the rapid damage estimation procedure is about half the IDR interval delimiting two performance levels. In other words, estimated IDR with an error of one- $\sigma$ will be off the mark at most by one performance level. Of course, on the average, the rapid estimation procedure performs rather well. Shown in Figure 12d are the fragilities for each of the performance levels (cumulative probability of exceedance of a given performance level as a function of PGV), computed using the actual and estimated IDRs. The IO, LS, and CP fragilities derived using estimated IDRs agree very well with those derived using actual IDRs, with probability of exceedance not differing by more than $3 \%$. The estimation procedure overpredicts the probability of exceedance of the RT and CO performance levels by up to $10 \%$.

Finally, the estimation of IDR under the near-source records described earlier is revisited using the modified rapid damage estimation procedure adopted for the San Andreas study. The results are summarized in Figure 13. The error in IDR now has a Gaussian mean of -0.001828 and a standard deviation of 0.00768 , both being marginally worse than the original direct estimation procedure. It may be prudent to classify records as near source or otherwise prior to adopting one estimation procedure or the other.

\section{Emergency Response}

In assessing the utility of rapid hazard assessment systems for emergency response, three factors must be considered: 
(a)

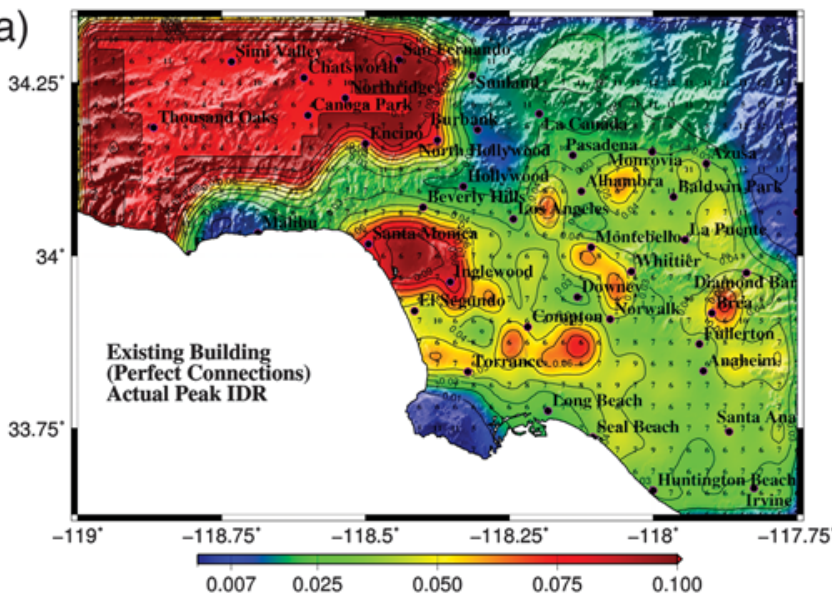

(c)

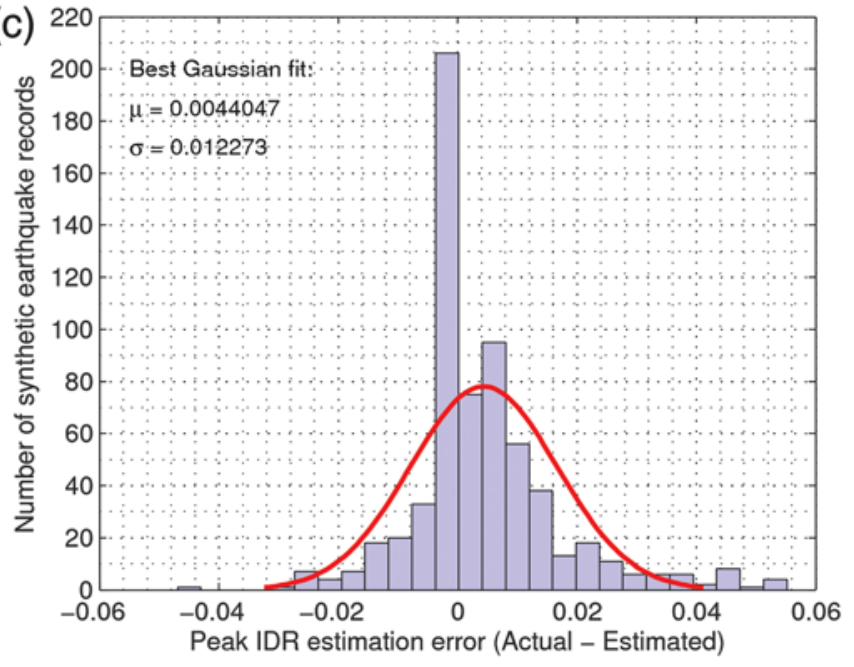

(b)

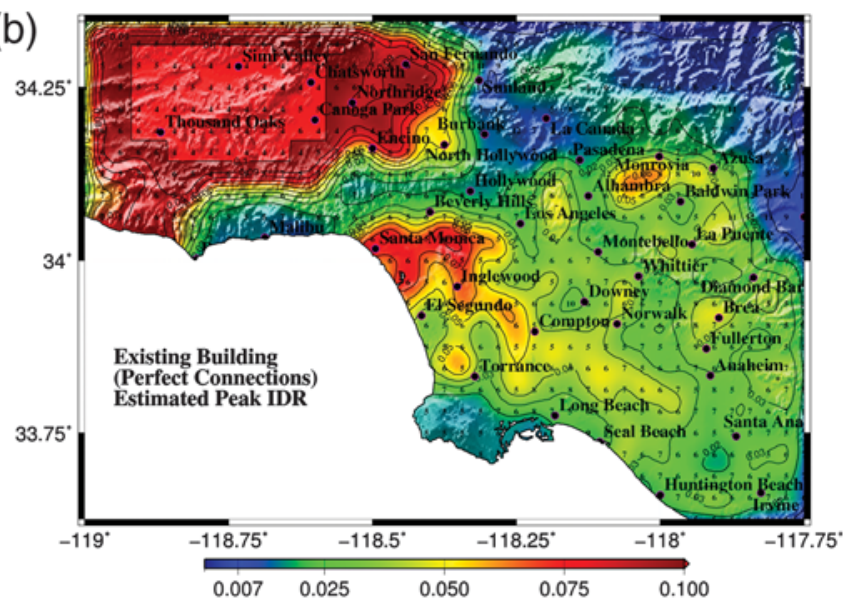

(d)

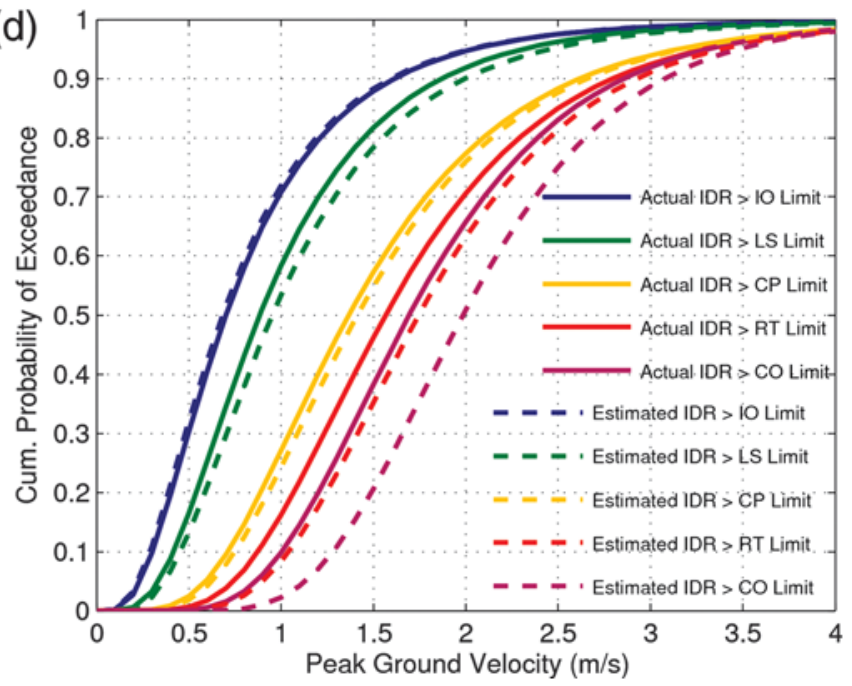

Figure 12. (a) Map of peak transient IDR in the 18-story building (perfect connections) computed using synthetic three-component waveforms at 636 sites from the 1857-like San Andreas earthquake simulation. (b) The corresponding map of estimated peak transient IDR computed with the modified rapid estimation approach using the best-fitting idealized sawtooth waveforms to the horizontal components of the synthetic motion. (c) Histogram of the estimation error and the best Gaussian fit. (d) Comparison of fragilities determined using computed responses in (a) and the estimated responses in (b). Note: Peak transient IDR is capped at 0.10.

(1) timeliness of results is more important than absolute accuracy; (2) results must be expressed in a simple straightforward metric; and (3) to the extent feasible, the assessment system must be integrated with systems already in use by response agencies. The preservation of life is the highest priority in an emergency response, and it is well established that a rapid and focused search and rescue effort is necessary to minimize the loss of life in collapse and near collapse situations. Furthermore, high-rise buildings are structures in which large numbers of people work or live and, if vulnerable to long-period motion from earthquakes, may become concentrated scenes of injured and entrapped persons. For instance, in the ShakeOut scenario of 2008, a total of 1800 deaths were posited to occur in a hypothetical magnitude 7.8 earthquake on the San Andreas fault (Jones et al., 2008; Porter et al., 2011). Of these, 439 deaths were attributed to the collapse of five high-rise steel MF buildings alone, 900 deaths to fire following the earthquake, and the rest were attributed to low-rise structure collapse. This clearly points to the heavy concentration of fatalities in high-rise structure collapses and the apparent need for swift all-out response.

The rapid identification of location and damage state of high-rise buildings is thus a critical component of emergency response. But the assessment must be timely, and if estimates of location and damage cannot be obtained within an hour or less from structural damage estimation systems such as the one described in this article, deployments of resources will proceed based on the best information available, typically from direct observation. From the standpoint of emergency management, it is important to assure that processing time does not increase with efforts to add parameters to, or increase the accuracy of, a damage estimation system. If, however, processing time does not suffer, additional information, such as the likely locations of survivable void space in individual collapsed buildings, would be of considerable value to search and rescue efforts. 
(a)

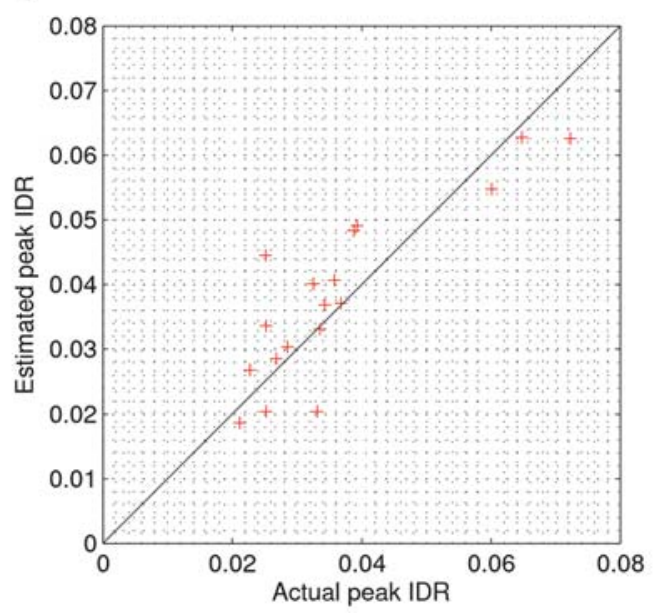

(b)

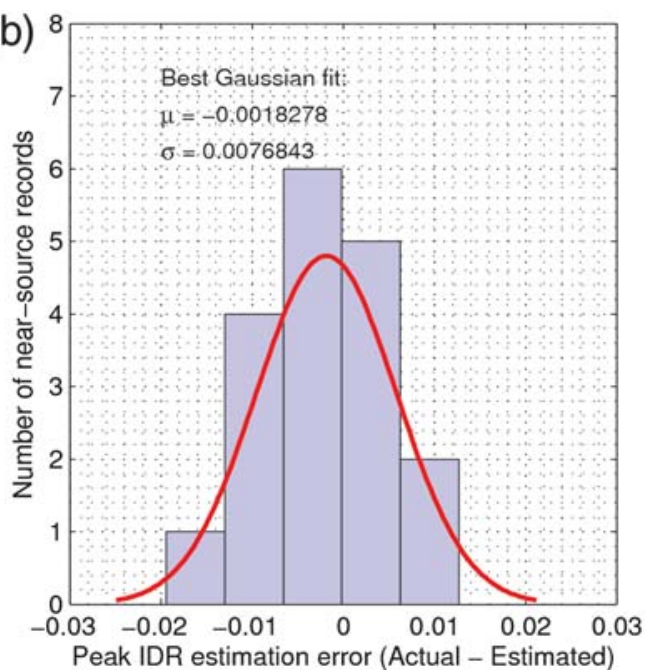

Figure 13. (a) Peak transient IDR computed using all near-source records plotted against those computed using not the best-fit idealized one-cycle sawtooth waveforms as in Figure 8, but the rapid estimation methodology adopted for the San Andreas case: existing building with susceptible connections. The diagonal line represents identical results from the two analyses. (b) Histogram of the error in determining the peak transient IDR from the idealized waveform representation as opposed to the actual record. The best-fit Gaussian is also shown.

Use of a simple metric and the integration of the damage estimation system described in this article into existing technologies employed by emergency managers are related. A peak IDR is not a concept common to emergency responders; however, if the transient IDR categories as described in Table 1 were zoned, expressed in mapped form, and integrated into the ShakeMap suite of ground-motion maps, the system would be readily available in a format commonly used in emergency response. Currently, postearthquake safety assessments are conducted according to the Applied Technology Council guidelines ATC-20 (Applied Technology Council, 1989). Structures are visually inspected, and their conditions are categorized using color codes. However, the safety assessment program is implemented in the days following a significant earthquake and is not designed as a real-time system. Reconciling the near real-time mapping capabilities of the rapid damage estimation system with the ATC-20 categories and packaging it in ShakeMap format may help facilitate its use by emergency response organizations.

\section{Discussion}

The near real-time system outlined here can be implemented in any metropolitan city in the world with a good seismic network and a well-constrained seismic model of wave speeds and density. Seismic data collected from past earthquakes is needed to accurately characterize the regional seismic structure of the earth. Similarly, strong-motion data collected during the target event, although not absolutely necessary, could be used to more accurately characterize the seismic source. A regional spectral-element model must be built and validated using simulations of past earthquakes. A computer model would need to be created from the structural drawings of each tall building in the city. The models need to be validated to the extent possible using available ambient vibration data, mobile-shaker forced vibration data, and/or past earthquake response measurements. Parametric analyses using the suite of idealized sawtooth ground-motion waveforms need to be performed and archived in a database in preparation for rapid estimation. To collect ground-shaking data from global and regional seismic networks, the near real-time system could plug in through the Internet and be set up to rapidly extract the relevant data for feeding into the source model generation algorithm. An on-demand cluster with 100 or more processors or an equivalent number of central processing unit cycles in a cloud would enable the implementation to be effective for swift emergency response. Rapid assessment and estimation of the location and damage state of high-rise steel frame buildings would be an important addition to existing real-time earthquake information currently available to emergency managers. To optimize its utility, IDR estimation systems should be rapidly available and in a metric and format already in use by responding agencies, particularly organizations that support and manage search and rescue operations. The assessment of aftershock effects could possibly be conducted using simulations of aftershock earthquake scenarios with seismic source models that are informed by the source of the mainshock. The detailed structural model could be analyzed under the synthetic mainshock ground motion followed after a brief lull by the synthetic aftershock ground motion to provide a realistic estimate of the expected outcome that could serve as a basis for the decision to red tag the building (similar to Yeo and Cornell, 2005, except that the decision would be based on nonlinear time-history analysis). This could be done over a 24-hour time frame and does not have to be conducted rapidly.

Finally, we should note that continuously monitoring the health of structures using dense instruments is perhaps the 
most reliable way of estimating damage and responding effectively (e.g., Kubo et al., 2011). While this has not been realized in the vast majority of present-day buildings for a variety of reasons (such as cost of maintenance, liability, and other reasons), the advent of cheap sensors mounted on USBs and smart phones provides a tremendous opportunity for extensive real-time monitoring. However, until such city-wide monitoring is implemented, simulation-based methods such as the one outlined in this article are the best alternative for rapid damage estimation.

\section{Limitations of the Study}

There are five noteworthy limitations of this study.

1. Only a single lateral force-resisting structural system is considered in this study: a steel MF system. A wide variety of structural systems are utilized in tall buildings and the applicability of the approach needs to be investigated for each system type. Having said this, steel MFs have been the structural system of choice for tall buildings in the 10-30 story range in the United States. Buildings in this height range form a major fraction of the tall building stock in the U.S. and in other parts of the world. For example, in 2007, 607 out of 656 tall buildings in the greater Los Angeles region were in the 10-30 story range.

2. The rapid estimation procedure is tested on a single scenario earthquake and a single building model. The examples presented in this prototype study are intended to simply establish a proof of concept. Evaluating the robustness of the approach and quantifying the errors associated with the procedure requires its application to a significantly greater number of earthquake scenarios and building models. In this context, the use of other groundmotion idealization schemes and optimization schemes need to be investigated.

3. The parametric analyses are conducted using single component excitation. The rapid response estimation approach will thus yield better results in cases where the strong ground-motion component is oriented in either one of the two principal directions of the buildings (or lateral force-resisting system). If the strongest shaking is not oriented in either principal direction of the building, the peak transient IDR response of the structure may be estimated as the square root of the sum of the squares of peak transient IDR from the two components of ground motion in the building principal directions $\left(\sqrt{I D R_{x}^{2}+I D R_{y}^{2}}\right)$.

4. Ground-velocity waveforms that have positive and negative phases with different amplitudes or that have an unequal number of positive and negative phases have not been considered in the parametric analyses of this prototype study, but should be included in real-world implementations.

5. As with any modeling techniques, FRAME3D models of buildings have limitations too: (1) Composite action of
MF beams has not been included. Moment-frame beams are connected to the concrete slab on metal deck through shear connectors (studs). A portion of the slab in the vicinity of the beam gets coupled to it, leading to increased stiffness and strength. The effect of this is twofold. First, it could make the MFs stiffer, attracting greater seismic forces, but this could be partly offset by the increased strength from composite action. Second, because this would make the beams stronger in relation to the columns, it could have the effect of pushing the location of plastic yielding into the columns. (2) Damage to floor slabs is not modeled. (3) Floor framing beams that support the dead weight of the floors are not modeled. While they are typically assumed to be pin connected, in reality they do offer partial restraint. Of course, the sections are much shallower and smaller than the MF beams. This factor, in conjunction with the fact that only partial restraint is offered by the connections, implies that their contribution may be quite small relative to the MF beams. (4) Local buckling of I-section flange plates is not included in the structural modeling. The fiber discretization used in our beam elements is not readily amenable to the incorporation of this failure mode. However, local buckling can be accounted for in a phenomenological manner by forcing a fiber to become inactive when a limiting compressive strain is reached. This failure mode becomes especially important when the structure nears the collapse limit state. This is the reason to resort to empirical damage limit states that are based on the peak IDR such as those proposed by FEMA. If local flange buckling is properly modeled, the computational models should start collapsing when peak transient IDR reaches 0.05-0.075. As it stands, gravity-driven progressive collapse invariably takes hold of our numerical models beyond peak transient IDRs of 0.10. (5) Column splices have not been modeled. Column splices are typically located three feet above the floor slab with the intention of locating them away from the high-moment (high flexural stress) regions near beam-column joints. In the absence of axial load, the theoretical point of contraflexure (zero moment) is at midheight of the column. In the case of columns, axial load does exist, and buckling failure could occur at midheight (first mode buckling). So the splice location of three feet above the floor slab is chosen to avoid the most vulnerable locations of the column. These splices are weak points and could fail, especially if the column goes into tension during the earthquake. (6) Stiffness and strength of partitions, and stair and elevator enclosures are not included. (7) Foundations and soil-structure interaction (SSI) have not been modeled. Past studies on a 14-story reinforced concrete storage building in Hollywood indicate that the change in various structural response parameters during the 1 October 1987, magnitude 5.9 Whittier Narrows earthquake due to SSI could have been up to $20 \%$ (e.g., Fenves and Serino, 1990). 


\section{Conclusions and Future Work}

We have presented a near real-time approach to estimate damage to tall buildings in the event of a large regional earthquake. The approach combines archived simulations of tall building response to idealized ground-motion waveforms with near real-time seismic source generation, and seismic-wave propagation and waveform generation algorithms to predict the building damage state. A hypothetical case study involving an 1857-like magnitude 7.9 San Andreas fault earthquake has been detailed. The rapid response algorithm takes a cumulative time of under two hours [63 minutes $($ SPECFEM) +51 minutes (ESTIMATION)] using 144 processors in a parallel computer to estimate tall building response at 636 sites in the greater Los Angeles region. The $1-\sigma$ predictions are within a single performance level of the exact damage state of the building in the entire simulation domain. The next steps would be to create a prototype rapid estimation product for southern California that extracts seismic source models from the USGS earthquakes gateway, automatically generates the ground motion at various sites [using a finite-source version of the Caltech ShakeMovie gateway (Tromp et al., 2011b)], and estimates responses of existing tall buildings in the greater Los Angeles region. The system could potentially be extended to estimating nonstructural component response that may be used to get a sense of plausible fatality levels. A catalog of southern California tall building models is being built within the Caltech Virtual Shaker project (Earthquake Engineering Research Laboratory, 2009). After the southern California rapid response estimation system is implemented successfully, it could be adapted for other megacities located in seismically active regions of the world.

\section{Data and Resources}

Some of the seismograms used in this study were downloaded from the COSMOS earthquake database (Regents of the University of California, 2011). Some plots were made using the Generic Mapping Tools version 4.1.4 (Wessel and Smith, 1998, 2011).

\section{Acknowledgments}

The authors would like to express their deep gratitude to Paul Jennings of the California Institute of Technology and three anonymous reviewers for their thorough review of this work. Their insightful comments have helped refine this article appreciably. This study was funded in part by the U.S. National Earthquake Hazard Reduction Program (NEHRP Award Number G09AP00063) and the U.S. National Science Foundation (NSF Award Number EAR-PF 0848080), whose financial support is gratefully acknowledged. The authors would also like to acknowledge the central role of the Southern California Earthquake Center (SCEC) in advancing earth system science in southern California, directly benefiting many elements of this study.

\section{References}

Akçelik, V., J. Bielak, G. Biros, I. Epanomeritakis, A. Fernandez, O. Ghattas, E. J. Kim, J. Lopez, D. O'Hallaron, T. Tu, and J. Urbanic
(2003). High-resolution forward and inverse earthquake modeling on terascale computers, in Proc. of the ACM/IEEE Supercomputing SC 2003 Conf., Phoenix, Arizona, 15-21 November 2003, 52-72.

Amante, C., and B. W. Eakins (2009). ETOPO1 1 Arc-minute global relief model: Procedures, data sources, and analysis, Tech. Rept. NESDIS $N G D C-24$, National Geophysical Data Center, National Oceanic and Atmospheric Administration (NOAA), Boulder, Colorado, $25 \mathrm{pp}$.

Applied Technology Council (1989). ATC-20 Procedures for Postearthquake Safety Evaluation of Buildings, Applied Technology Council, Redwood City, California, 152 pp.

Bao, H., J. Bielak, O. Ghattas, L. F. Kallivokas, D. R. O'Hallaron, J. R. Shewchuk, and J. Xu (1998). Large-scale simulation of elastic wave propagation in heterogeneous media on parallel computers, Comput. Meth. Appl. Mech. Eng. 152, no. 1-2, 85-102.

Bassin, C., G. Laske, and G. Masters (2000). The current limits of resolution for surface wave tomography in North America, Eos Trans. AGU, 81, F897.

Bazzurro, P., C. A. Cornell, C. Menun, and M. Motahari (2004). Guidelines for seismic assessment of damaged buildings, in Proc. of the 13th World Conf. on Earthquake Engineering, Vancouver, British Columbia, Canada, 1-5 August 2004, paper no. 1708.

Berg, G. V., and S. S. Thomaides (1960). Energy consumption by structures in strong-motion earthquakes, in Proc. of the 2nd World Conf. on Earthquake Engineering, Tokyo, Japan, 11-18 July 1960, 681-696.

Bizzarri, A. (2011). On the deterministic description of earthquakes, Rev. Geophys. 49, no. RG3002, 32, doi: 10.1029/2011RG000356.

Carlson, A. (1999). Three-dimensional nonlinear inelastic analysis of steel moment frame buildings damaged by earthquake excitations. Tech. Rept. EERL 99-02, Earthquake Engineering Research Laboratory, California Institute of Technology, Pasadena, California.

Casarotti, E., M. Stupazzini, S. Lee, D. Komatitsch, A. Piersanti, and J. Tromp (2008). CUBIT and seismic wave propagation based upon the spectral-element method: An advanced unstructured mesher for complex 3D geological media, in Proc. of the 16th International Meshing Roundtable, Seattle, Washington, 14-17 October 2008, 579-597.

Chi, W., S. El-Tawil, G. G. Deierlein, and J. F. Abel (1998). Inelastic analyses of a 17-story steel framed building damaged during Northridge, Eng. Struct. 20, no. 4-6, 481-495.

Chiroiu, L. (2005). Damage assessment the 2003 Bam, Iran, earthquake using Ikonos imagery, Earthquake Spectra 21, no. S1, 219-224.

Clinton, J. F., E. Hauksson, and K. Solanki (2006). An evaluation of the SCSN moment tensor solutions: Robustness of the $M_{\mathrm{w}}$ magnitude scale, style of faulting, and automation of the method, Bull. Seismol. Soc. Am. 96, no. 5, 1689-1705.

Clough, R. W., and J. Penzien (1993). Dynamics of Structures, Second Ed., McGraw-Hill, Upper Saddle River, New Jersey, 738 pp.

DeDontney, N., J. R. Rice, and R. Dmowska (2011). Influence of material contrast on fault branching behavior, Geophys. Res. Lett. 38, L14305, doi: 10.1029/2011GL047849.

Durek, J., and G. Ekström (1996). A radial model of anelasticity consistent with long-period surface-wave attenuation, Bull. Seismol. Soc. Am. 86, 144-158.

Dziewonski, A., T.-A. Chou, and J. Woodhouse (1981). Determination of earthquake source parameters from waveform data for studies of global and regional seismicity, J. Geophys. Res. 86, no. B4, 2825-2852.

Eberhart-Phillips, D., P. J. Haeussler, J. T. Freymueller, A. D. Frankel, C. M. Rubin, P. Craw, N. A. Ratchkovski, G. Anderson, G. A. Carver, A. J. Crone, T. E. Dawson, H. Fletcher, R. Hansen, E. L. Harp, R. A. Harris, D. P. Hill, S. Hreinsdóttir, R. W. Jibson, L. M. Jones, R. Kayen, D. K. Keefer, C. F. Larsen, S. C. Moran, S. F. Personius, G. Plafker, B. Sherrod, K. Sieh, N. Sitar, and W. K. Wallace (2003). The 2002 Denali fault earthquake, Alaska: A large magnitude, slip-partitioned event, Science 300, 1113-1118.

Ely, G., T. H. Jordan, P. Small, and P. J. Maechling (2010). A $V_{s}-30$ derived near-surface seismic velocity model, in Proc. of the American Geophysical 
Union Fall Meeting, San Francisco, California, 13-17 December 2010, abstract S51A-1907.

FEMA (2000). Prestandard and Commentary for the Seismic Rehabilitation of Buildings, FEMA 356. Federal Emergency Management Agency, Washington, D.C., 518 pp.

Fenves, G. L., and G. Serino (1990). Soil-structure interaction in buildings from earthquake records, Earthquake Spectra 6, no. 4, 641-655.

Gehbauer, F., M. Markus, H. Engelmann, I. Popa, C. Schweier, M. Rehor, and S. Werder (2007). The disaster management tool (DMT), in Proc. of the International Symposium on Strong Vrancea Earthquakes and Risk Mitigation, Bucharest, Romania, 4-6 October 2007.

Goel, S. C., and G. V. Berg (1968). Inelastic earthquake response of tall steel frames, J. Struct. Div. 94, no. 8, 834-1907.

Graves, R. W. (1998). Three-dimensional finite-difference modeling of the San Andreas fault: Source parameterization and ground-motion levels, Bull. Seismol. Soc. Am. 88, no. 4, 881-897.

Graves, R. W., B. T. Aagaard, K. W. Hudnut, L. M. Star, J. P. Stewart, and T. H. Jordan (2008). Broadband simulations for $M_{\mathrm{w}} 7.8$ southern San Andreas earthquakes: Ground motion sensitivity to rupture speed, Geophys. Res. Lett. 35, L22302, doi: 10.1029/2008GL035750.

Guatteri, M., P. M. Mai, G. C. Beroza, and J. Boatwright (2003). Strong ground-motion prediction from stochastic-dynamic source models, Bull. Seismol. Soc. Am. 93, no. 1, 301-313.

Hall, J. F., T. H. Heaton, M. W. Halling, and D. J. Wald (1995). Near-source ground motion and its effects on flexible buildings, Earthquake Spectra 11, no. 4, 569-605.

Harris, R., M. Barall, R. Archuleta, B. Aagaard, J. P. Ampuero, H. Bhat, V. Cruz-Atienza, L. Dalguer, P. Dawson, S. Day, B. Duan, E. Dunham, G. Ely, Y. Kaneko, Y. Kase, N. Lapusta, Y. Liu, S. Ma, D. Oglesby, K. Olsen, A. Pitarka, S. Song, and E. Templeton (2009). The SCECUSGS dynamic earthquake rupture code verification exercise, Seismol. Res. Lett. 80, 119-126.

Hartzell, S. H., P. Liu, and C. Mendoza (1996). The 1994 Northridge, California, earthquake: Investigation of rupture velocity, risetime, and high-frequency radiation, J. Geophys. Res. 101, no. B9, 20,091-20,108.

Hauksson, E. (2000). Crustal structure and seismicity distribution adjacent to the Pacific and North American plate boundary in southern California, J. Geophys. Res. 105, 13,875-13,903.

Hayashi, H., S. Hashitera, M. Kohiyama, N. Matsuoka, N. Maki, H. Fujita, and C. D. Elvidge (2000). International collaboration for the early damaged area estimation system using DMSP/OLS nighttime images, in Proc. International Geoscience and Remote Sensing Symposium, Honolulu, Hawaii, 24-28 July 2000, 2697-2699, doi: 10.1109/ IGARSS.2000.859685.

Heaton, T. H., J. F. Hall, D. J. Wald, and M. W. Halling (1995). Response of high-rise and base-isolated buildings to a hypothetical $M_{\mathrm{w}} 7.0$ blind thrust earthquake, Science 267, 206-211.

Hosokawa, M., B.-P. Jeong, and O. Takizawa (2007). Earthquake damage detection using remote sensing data, in Proc. Geoscience and Remote Sensing Symposium, Barcelona, Spain, 23-28 July 2007, 2989-2991, doi: 10.1109/IGARSS.2007.4423473.

Huyck, C. K., B. J. Adams, S. Cho, H.-C. Chung, and R. T. Eguchi (2005). Towards rapid citywide damage mapping using neighborhood edge dissimilarities in very high-resolution optical satellite imageryApplication to the 2003 Bam, Iran, earthquake, Earthquake Spectra 21, no. S1, 255-266.

Ji, C., Y. Tan, D. Helmberger, and J. Tromp (2003). Modeling teleseismic $P$ and $S H$ static offsets for great strike-slip earthquakes, in Proc. of the American Geophysical Union Fall Meeting, San Francisco, California, 8-12 December 2003, abstract S12A-0369.

Ji, C., D. J. Wald, and D. V. Helmberger (2002). Source description of the 1999 Hector Mine, California, earthquake, Part I: Wavelet domain inversion theory and resolution analysis, Bull. Seismol. Soc. Am. 92, no. 4, 1192-1207.

Jones, L. M., R. Bernknopf, D. Cox, J. Goltz, K. Hudnut, M. Mileti, S. Perry, D. Ponti, K. Porter, M. Rechle, H. Seligson, K. Shoaf, J. Treiman, and
A. Wein (2008). The ShakeOut scenario, U.S. Geol. Surv. Tech. Rept. Open-File Rept. 2008-1150.

Kellogg, L. (2011). Computational Infrastructure for Geodynamics, http:// geodynamics.org (last accessed June 2011).

Kohiyama, M., H. Hayashi, N. Maki, M. Higashida, H. W. Kroehl, C. D. Elvidge, and V. R. Hobson (2004). Early damaged area estimation system using DMSP-OLS night-time imagery, Int. J. Rem. Sens. 25, no. 11, 2015-2036.

Kohler, M., H. Magistrale, and R. Clayton (2003). Mantle heterogeneities and the SCEC three-dimensional seismic velocity model version 3, Bull. Seismol. Soc. Am. 93, 757-774.

Komatitsch, D. (2011). Fluid-solid coupling on a cluster of GPU graphics cards for seismic wave propagation, Comptes Rendus de l'Académie des Sciences-Mécanique 339, 125-135.

Komatitsch, D., and J. Tromp (1999). Introduction to the spectral element method for three-dimensional seismic wave propagation, Geophys. $J$. Int. 139, 806-822.

Komatitsch, D., G. Erlebacher, D. Göddeke, and D. Michéa (2010). High-order finite-element seismic wave propagation modeling with MPI on a large GPU cluster, J. Comput. Phys. 229, no. 20, 7692-7714.

Komatitsch, D., Q. Liu, J. Tromp, P. Süss, C. Stidham, and J. H. Shaw (2004). Simulations of ground motion in the Los Angeles basin based upon the spectral-element method, Bull. Seismol. Soc. Am. 94, 187-206.

Earthquake Engineering Research Laboratory (2009). The Caltech Virtual Shaker, http://virtualshaker.caltech.edu, California Institute of Technology (last accessed June 2010).

Krishnan, S., and M. Muto (2011). Mechanism of collapse, sensitivity to ground motion features, and rapid estimation of the response of tall steel moment frame buildings to earthquake excitation, Tech. Rept. EERL 2011-02, Earthquake Engineering Research Laboratory, California Institute of Technology, Pasadena, California.

Krishnan, S., C. Ji, D. Komatitsch, and J. Tromp (2006a). Case studies of damage to tall steel moment-frame buildings in Southern California during large San Andreas earthquakes, Bull. Seismol. Soc. Am. 96, no. $4,1523-1537$.

Krishnan, S., C. Ji, D. Komatitsch, and J. Tromp (2006b). Performance of two 18-story steel moment-frame buildings in Southern California during two large simulated San Andreas earthquakes, Earthquake Spectra 22, no. 4, 1035-1061.

Kubo, T., Y. Hisada, S. Horiuchi, and S. Yamamoto (2008). Application of earthquake early warning system and real-time strong-motion monitoring system to earthquake disaster mitigation of a high-rise building in Tokyo, Japan, in Proc. of the 14th World Conf. on Earthquake Engineering, Beijing, China, 12-17 October 2008, paper no. S10-058.

Kubo, T., Y. Hisada, M. Murakami, F. Kosuge, and K. Hamano (2011). Application of an earthquake early warning system and a real-time strong motion monitoring system in emergency response in a high-rise building, Soil Dynam. Earthquake Eng. 31, no. 2, 231-239.

Kustowski, B., G. Ekström, and A. M. Dziewoński (2008). Anisotropic shear-wave velocity structure of the earth's mantle: A global model, J. Geophys. Res. 113, B06306, doi: 10.1029/2007JB005169.

Lapusta, N., and Y. Liu (2009). Three-dimensional boundary integral modeling of spontaneous earthquake sequences and aseismic slip, J. Geophys. Res. 114, B01311, doi: 10.1029/2008JB005934

Lin, G., P. M. Shearer, E. Hauksson, and C. H. Thurber (2007). A threedimensional crustal seismic velocity model for Southern California from a composite event method, J. Geophys. Res. 112, B11306, doi: 10.1029/2007JB004977.

Liu, Q., J. Polet, D. Komatitsch, and J. Tromp (2004). Spectral-element moment tensor inversions for earthquakes in Southern California, Bull. Seismol. Soc. Am. 94, no. 5, 1748-1761.

Magistrale, H., S. Day, R. Clayton, and R. Graves (2000). The SCEC Southern California reference three-dimensional seismic velocity model version 2, Bull. Seismol. Soc. Am. 90, no. 6B, S65-S76. 
Magistrale, H., K. McLaughlin, and S. Day (1996). A geology-based 3D velocity model of the Los Angeles basin sediments, Bull. Seismol. Soc. Am. 86, 1161-1166.

Mahin, S. A., and J. Lin (1983). Construction of inelastic response spectrum for single degree of freedom system, Tech. Rept. UCB/EERC-83-17, Earthquake Engineering Research Center, University of California, Berkeley, California.

Markus, M., F. Fiedrich, J. Leebmann, C. Schweier, and E. Steinle (2004). Concept for an integrated disaster management tool, in Proc. of the 13th World Conf. on Earthquake Engineering, Vancouver, British Columbia, Canada, 1-6 August 2004, paper no. 3094.

Matsuoka, M., and N. Nojima (2010). Building damage estimation by integration of seismic intensity information and satellite L-band SAR imagery, Int. J. Rem. Sens. 2, no. 9, 2111-2126.

Muto, M., and S. Krishnan (2011). Hope for the best, prepare for the worst: Response of tall steel buildings to the shakeout scenario earthquake, Earthquake Spectra 27, no. 2, 375-398.

Olsen, K. B., R. J. Archuleta, and J. R. Matarese (1995). Three-dimensional simulation of a magnitude 7.75 earthquake on the San Andreas fault, Science 270, 1628-1632.

Olsen, K. B., S. M. Day, L. A. Dalguer, J. Mayhew, Y. Cui, J. Zhu, V. M. Cruz-Atienza, D. Roten, P. Maechling, T. Jordan, D. Okaya, and A. Chourasia (2009). ShakeOut-D: Ground motion estimates using an ensemble of large earthquakes on the southern San Andreas fault with spontaneous rupture propagation, Geophys. Res. Lett. 36, L04303, doi: 10.1029/2008GL036832.

Olsen, K. B., S. M. Day, J. B. Minster, Y. Cui, A. Chourasia, D. Okaya, P. Maechling, and T. Jordan (2008). TeraShake2: Spontaneous rupture simulations of $M_{\mathrm{w}} 7.7$ earthquakes on the southern San Andreas fault, Bull. Seismol. Soc. Am. 98, no. 3, 1162-1185.

Plesch, A., C. Tape, R. Graves, J. H. Shaw, P. Small, and G. Ely (2011). Updates for the CVM-H including new representations of the offshore Santa Maria and San Bernardino basins and a new Moho surface, in Proc. of the SCEC 2011 Annual Meeting, Southern California Earthquake Center, Palm Springs, California, 11-14 September 2011, poster B-128.

Porter, K. A., L. Jones, D. Cox, J. Goltz, K. Hudnut, D. Mileti, S. Perry, D. Ponti, M. Reichle, A. Rose, C. Scawthorn, H. A. Seligson, K. Shoaf, J. Treiman, and A. Wein (2011). The ShakeOut scenario: A hypothetical $M_{\mathrm{w}} 7.8$ earthquake on the southern San Andreas fault, Earthquake Spectra 27, no. 2, 239-262.

Portnoy, S., and R. Koenker (1997). The Gaussian hare and the Laplacian tortoise: Computability of squared-error vs. absolute-error estimators, with discussion, Stat. Sci. 12, no. 4, 279-300.

Prindle, K., and T. Tanimoto (2006). Teleseismic surface wave study for $S$-wave velocity structure under an array: Southern California, Geophys. J. Int. 166, no. 2, 601-621.

Rathje, E. M., and B. J. Adams (2008). The role of remote sensing in earthquake science and engineering: Opportunities and challenges, Earthquake Spectra 24, no. 2, 471-492.

Regents of the University of California (2011). COSMOS Virtual Data Center, http://db.cosmos-eq.org (last accessed January 2011).

Rehor, M. (2007). Classification of building damages based on laser scanning data, in Proc. of the ISPRS Workshop: Laser Scanning 2007, Espoo, Finland, 12-14 September 2007, 326-331.

Rehor, M., and H. P. Bahr (2007). Detection and analysis of building damage caused by earthquakes using laser scanning data, in Proc. of the International Symposium on Strong Vrancea Earthquakes and Risk Mitigation, Bucharest, Romania, 4-6 October 2007.

SAC (1995). Analytical and field investigations of buildings affected by the Northridge earthquake of January 17, 1994—Part 1, Tech. Rept. SAC 95-04, Part 1, Structural Engineers Association of California, Applied Technology Council, and California Universities for Research in Earthquake Engineering, Redwood City, California.

Saeki, T., H. Tsubokawa, and K. Shiomi (1999). A survey of earthquake damage assessments executed by the local governments post the Hyogo-Ken Nanbu earthquake, J. Soc. Safety Sci. 1, 165-172.
Saito, K., R. J. S. Spence, and T. A. d. C. Foley (2005). Visual damage assessment using high-resolution satellite images following the 2003 Bam, Iran, earthquake, Earthquake Spectra 21, no. S1, 309-318.

Saito, K., R. J. S. Spence, C. Going, and M. Markus (2004). Using highresolution satellite images for post-earthquake building damage assessment: A study following the 26 January 2001 Gujarat earthquake, Earthquake Spectra 20, no. 1, 145-169.

Sandia National Laboratories (2011). CUBIT: Geometry and Mesh Generation Toolkit, http://cubit.sandia.gov (last accessed November 2011).

Schmedes, J., R. J. Archuleta, and D. Lavallée (2010). Correlation of earthquake source parameters inferred from dynamic rupture simulations, $J$. Geophys. Res. 115, B03304, doi: 10.1029/2009JB006689.

Sieh, K. E. (1978). Slip along the San Andreas fault associated with the great 1857 earthquake, Bull. Seismol. Soc. Am. 68, no. 5, 1421-1448.

Süss, M. P., and J. H. Shaw (2003). $P$ wave seismic velocity structure derived from sonic logs and industry reflection data in the Los Angeles basin, California, J. Geophys. Res. 108, no. B3, article no. 2170, doi: 10.1029/2001JB001628.

Tape, C., Q. Liu, A. Maggi, and J. Tromp (2009). Adjoint tomography of the southern California crust, Science 325, no. 5943, 988-992.

Tape, C., Q. Liu, A. Maggi, and J. Tromp (2010). Seismic tomography of the southern California crust based on spectral-element and adjoint methods, Geophys. J. Int. 180, no. 1, 433-462.

Tromp, J., B. Guthe, C. Hillegas, R. Knight, J. Moraca, D. McRitchie, K. Perry, S. Su, E. Bozdag, V. Hjorleifsdottir, D. Komatitsch, Q. Liu, D. Peter, and P. Friberg (2011a). ShakeMovie Global, Princeton University, http://global.shakemovie.princeton.edu (last accessed June 2011).

Tromp, J., D. Komatitsch, V. Hjörleifsdóttir, Q. Liu, H. Zhu, D. Peter, E. Bozdag, D. McRitchie, P. Friberg, C. Trabant, and A. Hutko (2010). Near real-time simulations of global CMT earthquakes, Geophys. J. Int. 183, 381-389.

Tromp, J., D. Komatitsch, and Q. Liu (2008). Spectral-element and adjoint methods in seismology, Comm. Comput. Phys. 3, no. 1, 1-32.

Tromp, J., Q. Liu, P. Friberg, E. Hauksson, M. Vinci, S. Krishnan, J. McCorquodale, S. Lombeyda, and R. Yip and others (2011b). Southern California ShakeMovie, http://shakemovie.caltech.edu (last accessed June 2011).

Uang, C.-M., and V. V. Bertero (1986). Earthquake simulation tests and associated studies of a 0.3 -scale model of a six-story concentrically braced structure, Tech. Rept. UCB/EERC-86-10, Earthquake Engineering Research Center, University of California, Berkeley, California.

Uang, C.-M., and V. V. Bertero (1988). Use of energy as a design criterion in earthquake-resistant design, Tech. Rept. UCB/EERC-88-18, Earthquake Engineering Research Center, University of California, Berkeley, California.

Uang, C.-M., and V. V. Bertero (1990). Evaluation of seismic energy in structures, Earthquake Eng. Struct. Dynam. 19, no. 1, 77-90.

U.S. Geological Survey (2011). Earthquake Hazards Program, http://earthquake .usgs.gov/earthquakes/ (last accessed October 2011).

Wald, D. J., T. H. Heaton, and K. W. Hudnut (1996). The slip history of the 1994 Northridge, California, earthquake determined from strongmotion, teleseismic, GPS, and leveling data, Bull. Seismol. Soc. Am. 86, S49-S70.

Wehr, A., and U. Lohr (1999). Airborne laser scanning-An introduction and overview, ISPRS J. Photogrammetry Rem. Sens. 54, 68-82.

Wessel, P., and W. H. F. Smith (1998). New, improved version of the Generic Mapping Tools released, Eos Trans. AGU 79, no. 47, 579.

Wessel, P., and W. H. F. Smith (2011). Generic Mapping Tools, http://gmt .soest.hawaii.edu/, University of Hawaii, School of Ocean and Earth Science and Technology (last accessed October 2011).

Yamaguchi, N., T. Iwasaki, K. Mizukoshi, I. Suetomi, and F. Yamazaki (2004). Real-time damage estimation of buildings using the limit strength method, in Proc. of the 13th World Conf. on Earthquake Engineering, Vancouver, British Columbia, Canada, 1-6 August 2004, paper no. 1390. 
Yamazaki, F., Y. Yano, and M. Matsuoka (2005). Visual damage interpretation of buildings in Bam City using QuickBird images following the 2003 Bam, Iran, earthquake, Earthquake Spectra 21, no. 1, 329-336.

Yeo, G. L., and A. C. Cornell (2005). Stochastic characterization and decision bases under time-dependent aftershock risk in performance-based earthquake engineering, Tech. Rept. PEER 2005/13, Pacific Earthquake Engineering Research Center, Berkeley, California.

Yusuf, Y., M. Matsuoka, and F. Yamazaki (2002). Detection of building damages due to the 2001 Gujarat, India, earthquake using satellite remote sensing, in 7th U.S. National Conf. on Earthquake Engineering, Boston, Massachusetts, 21-25 July 2002.

California Institute of Technology

Pasadena, California 91125

krishnan@caltech.edu

ramses@caltech.edu

(S.K., R.M.)

Istituto Nazionale di Geofisica e Vulcanologia

Rome, Italy

emanuele.casarotti@ingv.it

(E.C.)

California Emergency Management Agency

Mather, California 95655

jim.goltz@calema.ca.gov

(J.G.)

University of California

Santa Barbara, California 93106

ji@geol.ucsb.edu

(C.J.)
CNRS/Aix-Marseille University

Marseille, France

komatitsch@1ma.cnrs-mrs.fr

(D.K.)

Southern California Edison

San Dimas, California 91773

matthew.muto@sce.com

(M.M.)

Harvard University

Cambridge, Massachusetts 02138

shaw@eps.harvard.edu

(J.H.S.)

University of Alaska Fairbanks

Fairbanks, Alaska 99775

carltape@gi.alaska.edu

(C.T.)

Princeton University

Princeton, New Jersey 08544

jtromp@princeton.edu

(J.T.) 